Review

\title{
Cellulases from Thermophiles Found by Metagenomics
}

\author{
Juan-José Escuder-Rodríguez, María-Eugenia DeCastro, María-Esperanza Cerdán (iD, \\ Esther Rodríguez-Belmonte, Manuel Becerra ${ }^{(D)}$ and María-Isabel González-Siso * (D) \\ Grupo EXPRELA, Centro de Investigacións Científicas Avanzadas (CICA), Departamento de Bioloxía, \\ Facultade de Ciencias, Universidade da Coruña, 15071 A Corunna, Spain; j.escuder@udc.es (J.-J.E.-R.); \\ m.decastro@udc.es (M.-E.D.); esper.cerdan@udc.es (M.-E.C.); esther.belmonte@udc.es (E.R.-B.); \\ manuel.becerra@udc.es (M.B.) \\ * Correspondence: migs@udc.es; Tel.: +34-981-167-000
}

Received: 21 June 2018; Accepted: 5 July 2018; Published: 10 July 2018

\begin{abstract}
Cellulases are a heterogeneous group of enzymes that synergistically catalyze the hydrolysis of cellulose, the major component of plant biomass. Such reaction has biotechnological applications in a broad spectrum of industries, where they can provide a more sustainable model of production. As a prerequisite for their implementation, these enzymes need to be able to operate in the conditions the industrial process requires. Thus, cellulases retrieved from extremophiles, and more specifically those of thermophiles, are likely to be more appropriate for industrial needs in which high temperatures are involved. Metagenomics, the study of genes and gene products from the whole community genomic DNA present in an environmental sample, is a powerful tool for bioprospecting in search of novel enzymes. In this review, we describe the cellulolytic systems, we summarize their biotechnological applications, and we discuss the strategies adopted in the field of metagenomics for the discovery of new cellulases, focusing on those of thermophilic microorganisms.
\end{abstract}

Keywords: cellulases; thermophiles; metagenomics; biotechnology

\section{Introduction}

Cellulose is a complex polymer that can be hydrolyzed into glucose by the synergetic action of a mixture of enzymes known as cellulases. Plants fix atmospheric $\mathrm{CO}_{2}$ and incorporate about half of the carbon in structural polysaccharides and lignin (lignocellulose). This structural carbon can be used as an energy source by cellulolytic microorganisms [1]. The cellulolytic enzymes can form an enzyme complex known as the cellulosome, in which they are anchored to a common scaffold. This structure is mostly observed in anaerobes and exclusively in bacteria. They can also act as non-complexed extracellular free cellulase systems, more often associated to aerobes and present in fungi, bacteria, and archaea [1-4]. Additionally, other auxiliary enzymes like lytic polysaccharide monooxygenases have been reported to also contribute to the degradation of cellulose by cellulases by enhancing their activity [5-7]. An enhancer effect has also been proposed for hemicellulases such as xylanases, mannanases, galactosidases, and $\beta-1,3-1,4$-glycanases, which has activity on polysaccharides present in plant biomass by allowing cellulases to better reach the substrate [8].

Microorganisms adapted to live in harsh conditions (from a human standpoint) are known as extremophiles. Their enzymes, and especially the extracellular ones, have adopted mechanisms to maintain their function in such environments and are known as extremozymes. They are interesting from a biotechnological perspective, as many industrial applications involve conditions similar to those of extreme environments, and a more sustainable production model would require biocatalysts able to operate in such conditions [9-11]. 
Thermophiles are extremophiles that thrive at high temperatures ranging from moderate thermophiles (capable of growth at temperatures between $50^{\circ} \mathrm{C}$ and $64^{\circ} \mathrm{C}$ ), extreme thermophiles (between $65^{\circ} \mathrm{C}$ and $79^{\circ} \mathrm{C}$ ), and hyperthermophiles (over $80^{\circ} \mathrm{C}$ ) [12]. Extreme habitats where these microorganisms can be found include deep-sea hydrothermal vents, hot springs, volcanic fields, mud pots and deserts, and human-made environments like compost, among others. Many enzymes of industrial importance have been retrieved from thermophiles, including cellulases [11].

\section{Modular Structure of Cellulases and their Classification}

Most cellulases have a modular design, in which two or more discrete units have cooperative functions and are connected through linker sequences. Usually, this modular design includes the catalytic domain linked to a carbohydrate-binding module (CBM), but other non-catalytic domains can also be present, and multiple catalytic domains or CBMs can exist on the same enzyme. The CBM helps in the catalytic process by increasing the concentration of the enzyme near the polysaccharides they bind $[5,13,14]$ and by disrupting the crystalline cellulose structure, increasing substrate accessibility [15]. As previously stated, some cellulases can form the enzyme complex known as the cellulosome, where they are anchored to a protein scaffold (composed of non-catalytic proteins known as scaffoldins). These cellulases contain dockerin domains that bind to the cohesin module of the scaffoldins, although these domains have also been described in proteins not related to the cellulosome [16]. In cellulosomes, the scaffolding proteins might also contain CBM modules [17].

The classic classification of cellulases is based on the mechanism of action of their catalytic domains and on their substrate specificity. This classification allows us to distinguish three major types of cellulases: $\beta$-1,4-endoglucanases (EC 3.2.1.4), exoglucanases [non-reducing end cellobiohydrolases (EC 3.2.1.91), reducing-end cellobiohydrolases (EC 3.2.1.176) and cellodextrinases (EC 3.2.1.74)], and $\beta$-glucosidases (EC 3.2.1.21) $[3,7,18]$. Endoglucanases act randomly cleaving internal glycosidic bonds of cellulose chains, releasing oligosaccharides of different length (like cellobiose and cellotriose). Cellobiohydrolases act processively on the reducing and non-reducing ends of cellulose, primarily releasing cellobiose but also other short oligosaccharides. Cellodextrinases act on soluble cellooligosaccharides, also releasing cellobiose. Lastly, $\beta$-glucosidases perform the hydrolysis of cellodextrins and cellobiose into glucose, enhancing both endoglucanase and exoglucanase activities by reducing the end product inhibition $[3,6,7,9]$. A schematic representation of cellulases acting on cellulose is depicted in Figure 1.

Due to the enormous variety of polysaccharides that exist in nature, and the fact that cellulases are not always easy to categorize as only endo- or exo-acting enzymes [19], an alternative classification based on amino acid sequence similarity was proposed [20]. Rather than substrate specificity, this classification addresses the structure-function relationships, substrate recognition and enzymatic reaction mechanisms, and evolutionary relationships between the enzymes. The publicly available Carbohydrate-Active Enzymes Database (CAZy, http://cazy.org) contains the classification of glycoside hydrolase $(\mathrm{GH})$ families in which the cellulases are included. The database at the time of writing lists 149 different GH families [21]. Endoglucanases are mainly present in $12 \mathrm{GH}$ families: GH5-9, GH12, GH44, GH45, GH48, GH51, GH74, and GH124; cellobiohydrolases acting on non-reducing ends can be found in families GH5, GH6, and GH9, whereas the reducing-end acting ones are mostly present in GH7, GH9, and GH48; cellodextrinases are distributed in families GH1, GH3, GH5, and GH9; and, lastly, $\beta$-glucosidases belong in families GH1-3, GH5, GH9, GH30, GH39, and GH116 [20]. 


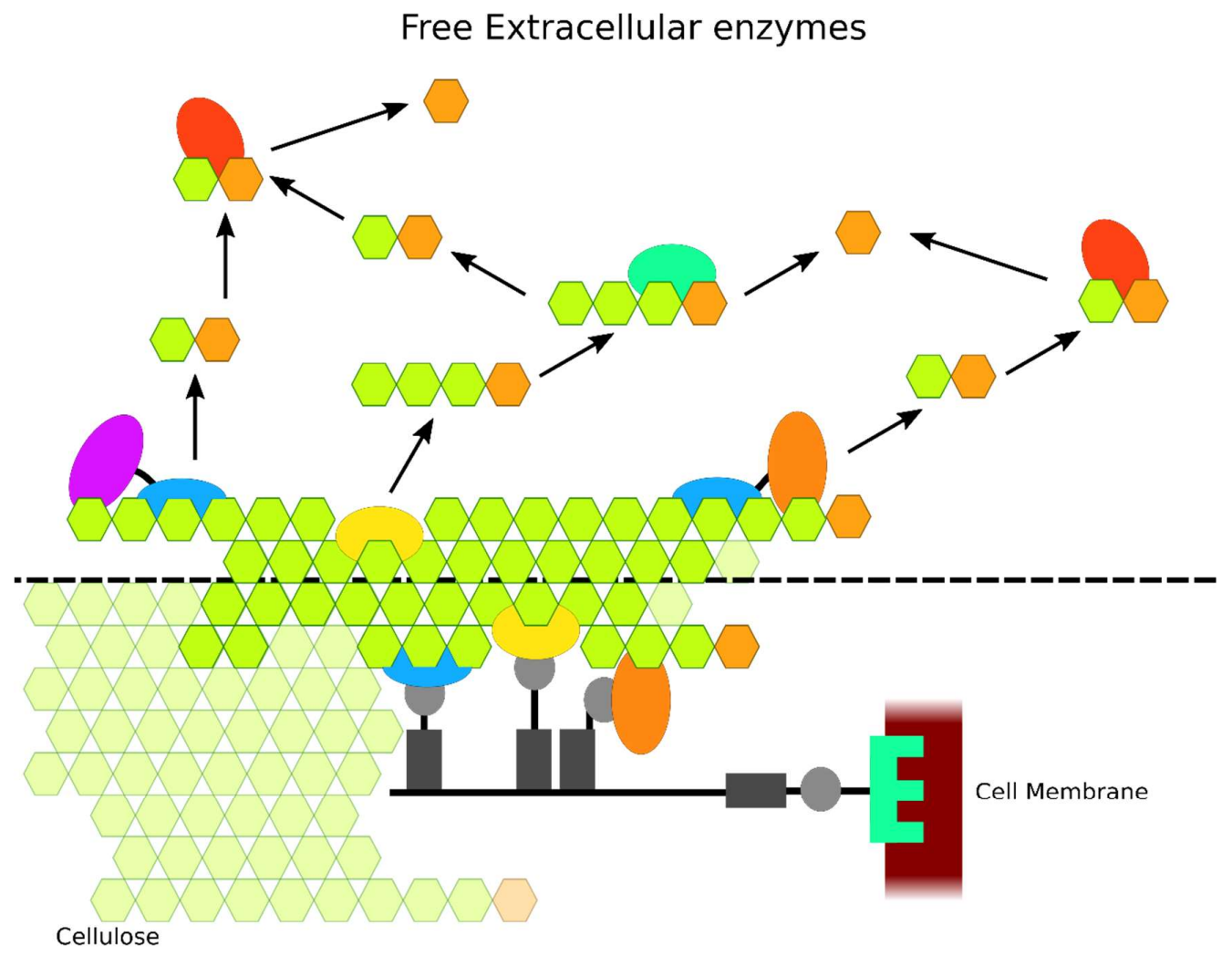

Cellulosome (cell membrane bound-enzymes)

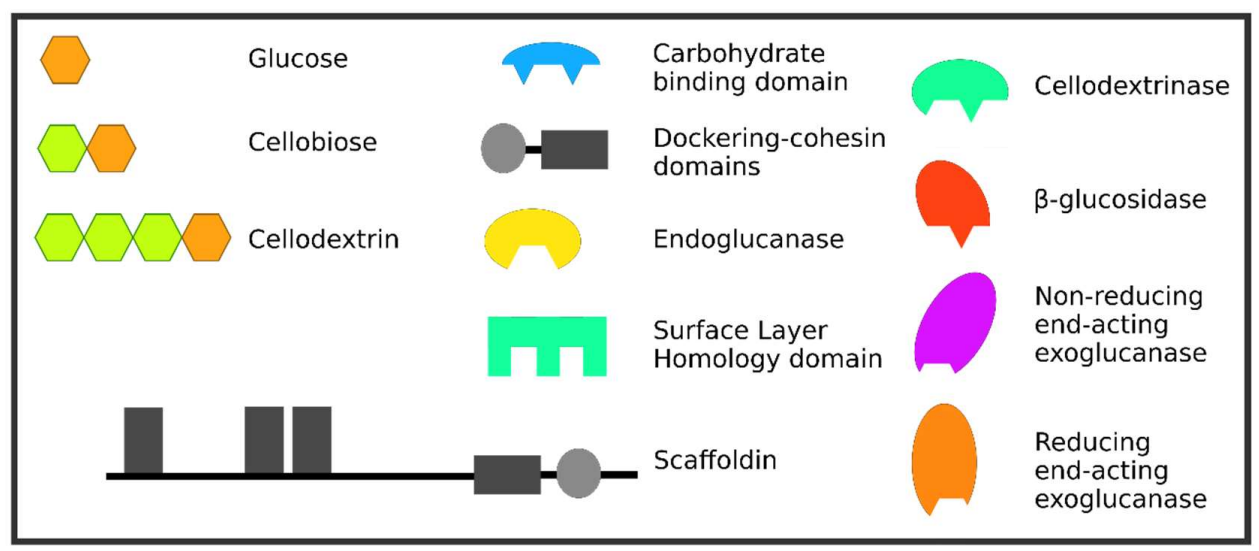

Figure 1. Overview of the two strategies (free or cell-bound cellulase systems) for degrading cellulose. In free extracellular systems, endoglucanases and exoglucanases act synergistically, with the endoglucanase cutting amorphous cellulose providing chain ends for exoglucanases to release cellobiose. Then, $\beta$-glucosidases complete the process of cellulose hydrolysis by releasing glucose. Also, cellodextrins released by endoglucanases can be further hydrolysed by cellodextrinases. The carbohydrate binding domain directs the enzymes to their specific substrates. In the cellulosome system, all cellulases are anchored to a common scaffold but are generally thought to follow the same synergic mode of action. The scaffolding is bound to the cell membrane through the surface layer homology domain, while a network of dockerin and cohesin domains amplifies the number of cellulases bound to the same scaffolding unit. Lastly, a carbohydrate binding domain is responsible for the targeting of the whole complex to the substrate. 
Even if they share structural characteristics, members of the same GH family may differ widely in substrate specificity and their evolutionary history, and, due to their multidomain nature, some enzymes may contain sequences from different $\mathrm{GH}$ families $[3,6,10]$. As a further classification for GHs, some families are also grouped in clans in regard to their folding, as it is more conserved than their amino acid sequence [14]. Clans are designated by a letter, and some cellulases fall inside these groups: GH-A (with a $(\beta / \alpha)_{8}$ barrel) includes cellulases from families GH1, GH2, GH5, GH30, GH39, and GH51; GH-B (that fold in $\beta$-jelly roll) contains family GH7; GH-C (also folding with a $\beta$-jelly roll) includes family GH12; GH-M (folding with a $(\alpha / \alpha)_{6}$ barrel) comprises families GH8 and GH48; and GH-O $\left[(\alpha / \alpha)_{6}\right.$ barrel folding] contains family GH116.

In regard to the catalytic mechanism, GHs (including cellulases) may perform the hydrolysis of the glycosidic bond by an inverting or retaining mechanism, whether the configuration of the substrate's anomeric carbon (C1) is changed or not after the cleavage. Retaining enzymes have a double nucleophilic displacement mechanism involving two carboxylate catalytic residues. Inverting enzymes act with a single nucleophilic displacement mechanism, also involving two carboxylate catalytic residues [1]. For cellulases, seven GH families have an inverting mechanism of catalysis (6, $8,9,45,48,74$, and 124), whereas eleven act with a retaining mechanism $(1-3,5,7,12,30,39,44,51$, and 116) $[20,22]$.

\section{Factors Influencing Thermostability of Thermophile Cellulases}

As pointed out, a greater half-life of cellulases at high temperatures is a desirable trait for many industrial applications. In order to obtain more thermostable variants of cellulases, the molecular mechanisms behind thermostability have been studied. Some researchers argue that the study of smaller, single-domain enzymes would make it easier to pinpoint the mechanisms involved in a higher resistance to high temperature [23], while others have studied the effect of the number of domains and linker sequences and domain-removal on thermostability, though opposing stabilizing and destabilizing effects have been described in this regard [5].

Several stabilization factors have been proposed for the increased thermostability of thermozymes, such an increased number of ion pairs, a lower number of loops and cavities (thus making the protein more compact), a reduced ratio of protein surface area to protein volume, a higher number of proline residues in loops (limiting the conformational freedom of the protein), an increased amount of hydrophobic interactions, and a greater degree of oligomerization [24,25]. Despite that, a direct correlation between all these factors and protein thermostability cannot always be established; for example, for Humicola insolens exoglucanase Cel6A the addition of proline residues in the loop regions did not achieve greater stability and in some instances had the opposite effect [26]. It has been also proposed that proteins can undergo structure-based or sequence-based stabilization strategies through evolution. As thermophilic archaea emerged in already extreme environments, their enzymes would initially favour stable folding at high temperatures, whereas thermophilic bacteria would have to enhance the thermostability of their proteins by point mutations that increase the number of ion-pairs in order to colonize the new habitats. Despite this theory, it has been found that among archaea, the two different stabilization models can be adopted [24].

There are also reports on how hydrophobic and aromatic residues can play a major role in protein thermal stability, like in the endoglucanase from family GH12 from Aspergillus niger [27]. Other authors have described an increased percentage of the charged amino acid glutamic acid in thermophilic enzymes from family GH12 compared to mesophilic ones, which is thought to stabilize the protein's structure through salt bridges and hydrogen bonds [23]. Moreover, some key residues for protein stability have been already identified in this protein family [1]. When comparing mesophilic and thermophilic exoglucanases from family GH7, the potential disulphide bridge formation by the presence of cysteine residues could not be linked to an increased thermostability, whereas a higher number of charged residues and lower number of polar residues was observed in the more 
thermostable enzymes [28]. However, it was found that rational mutagenesis introducing disulphide bridges in an exoglucanase from this family did allow the mutant proteins to be more thermostable [29].

Lastly, eukaryotes' post-translational modifications (including glycosylation, phosphorylation, acetylation, and methylation) have been reported to account for protein thermostability [27], and heterologous expression of the enzyme in a yeast host can be a desirable production system for industrial applications.

The yeast Pichia pastoris, in particular, has been extensively employed due to this property, along with its relative ease for genetic manipulation and high level of protein expression [19,30-32], coupled with inexpensive production media and relatively simple protein processing protocols [33]. Nevertheless, most studies regarding the discovery and the characterization of new thermophilic cellulases have involved the model organism Escherichia coli [34-38], sometimes at the expense of thermostability [39].

\section{Biotechnological Applications by Thermophile Cellulases}

Thermozymes have general advantages over their mesophilic counterparts in regard to their application in various industries, as they are generally more stable towards extreme temperatures and $\mathrm{pH}$, as well as in the presence of chemically destabilizing agents, and function at high temperatures with higher reaction rates [35] and higher mass-transfer rates that increase the substrates' solubility, as well as a lower risk of contamination [27]. Lastly, the process design gains flexibility (e.g., current process configurations with operations that needed pre-treatment of the substrates to lower the temperature can now be performed simultaneously without the requirement of a temperature modification between them), which in turn can reduce the cost of operation [27]. On the other hand, and as previously stated, preferred systems to produce these enzymes are not thermophilic, as thermophile production faces many technical challenges due to limited knowledge of their physiology and genetics, difficulty of growing and not being Generally Recognized As Safe [27] as defined by the US Food and Drug Administration under sections 201(s) and 409 of the Federal Food, Drug, and Cosmetic Act. In regard to the production process, extracellular enzymes are desirable, as they are easier to purify $[27,33]$.

The range of industries in which degradation of cellulose by cellulases is required is considerably wide and includes biofuels (conversion of plant biomass in bioethanol), food and brewing, textiles (biostoning and biopolishing), laundry (in detergent formulations), pulp and paper (biopulping), and animal feeds [35]. Other uses include waste management, improvement of soils for agriculture [40], and extraction of compounds from plants such as olive oil, pigments, and bioactive molecules [4].

The full conversion of cellulose into glucose, which can later be converted into ethanol (named bioethanol to stress it being a biofuel, in contrast with the classic fossil fuels) has been previously stated to require the combined action of multiple cellulolytic enzymes (endo- and exoglucanases and $\beta$-glucosidases). This process has gained a lot of interest, as plant biomass poses a promising renewable substrate alternative to assess the increasing energy demands while limiting the use of fossil fuels $[2,41]$. In this regard, the use of non-food lignocellulosic waste from agriculture and forestry has replaced food crops as the substrate of choice, as the use of the latter would have the associated risk of raising basic foods prices and limiting their supply [42]. In general, biorefining (using biomass as a substrate to produce fuels, energy, or chemicals) benefits from thermostable enzymes, as heat treatment, is an important step for the pre-processing of the lignocellulosic material [43-45]. The use of thermostable cellulases for the treatment and pretreatment of the biomass reduces the energy cost of the process, improves the solubility of the substrate, reduces its viscosity, and reduces dependency on the use of environmentally harsh chemicals $[39,45]$.

\subsection{Endoglucanase-Specific Industrial Applications}

Endoglucanases have been used in the textile industry for the process called biostoning. Biostoning achieves a wash-down look on denim cotton clothes, and represents an alternative to the chemical method using pumice stone. Biostoning has a number of advantages over the classical 
method, such as greater yields, less labor-intensive operations, more secure workplace, shorter time requirements, lower damage to the machinery, and a more environmentally friendly process [4].

Another textile industrial process in which endoglucanases are employed is the biopolishing of cotton products. This process removes the microfibrils from cottons' surfaces, enhancing the colour brightness and making them more resistant to pilling [40], as well as softening the product [46] and giving it a cleaner and smoother look [4]. Biopolishing is often performed after another enzymatic process called desizing (in which amylases remove starch from the fabrics). Desizing uses temperatures higher than $70{ }^{\circ} \mathrm{C}$, so endoglucanases operating at such temperatures would be interesting for combining both processes and thus reducing the required time and energy costs [46]. Other textile processes in which endoglucanases are employed to remove cellulosic impurities, replacing chemical treatments, include bio-carbonization of polyester-cotton blends, wool scouring, and de-fibrillation of Lyocell [4].

In the brewing industry, the production of malt generates high molecular weight $\beta$-glucans. The presence of these molecules increases viscosity, lowering the efficiency and yield of the process due to the increased difficulty for pumping and also making filtration difficult [33]. As such, the addition of endoglucanases would alleviate those problems, allowing for the hydrolysis of $\beta$-glucans [33]. Also, endoglucanases may be used to increase the extraction of fermentable compounds both in brewing and fermentation industries [47].

In the laundry industry, the use of endoglucanases in detergent formulations is known to improve the colour brightness and soften cotton fabrics [4], similarly to the biopolishing in the textile industry.

In the animal feed industry, they enhance $\beta$-glucan digestibility and nutrient bioavailability [47], and have been shown to increase weight gain and milk production of ruminants [4].

Endoglucanases have been extensively used in the pulp and paper industry for the treatment of pulp wastes [4,47], deinking and removal of pollutants from paper without altering its brightness and strength [4], and in the pulping process (bio-pulping), reducing the energy cost of the process and improving the beatability of the pulp [4].

\subsection{Exoglucanase-Specific Industrial Applications}

As in nature, efficient degradation of cellulose from biomass in industrial applications requires the synergic action of a mixture of cellulases [26,48]. Synergism has been described between endoglucanases and exoglucanases, between reducing-end-acting and non-reducing-end-acting exoglucanases, between processive endoglucanases and endo- or exoglucanases, and between $\beta$-glucosidases and the other cellulases [48]. As such, the previously described industrial applications benefit from the addition of exoglucanases to enzyme mixtures already containing other cellulase classes.

\section{3. $\beta$-glucosidase-Specific Industrial Applications}

In addition to their application in the last step of cellulose hydrolysis to release glucose, $\beta$-glucosidases have several additional biotechnological applications.

In the food industry, they can be used to release aromatic compounds from fruit and fermentation products [49], like the release of terpenoids and phenylpropanoids in wine to enhance its aroma [50,51]. Other uses include juice clarification [32] and hydrolysis of bitter compounds in its extraction [52], and, in general, improvement of quality of beverages and foods [44] including colour, aroma, flavour, texture, and nutritional value [4].

In the pharmaceutical industry, they are used to deglycosylate ginsenosides, active compounds with many pharmaceutical uses, as the natural glycosylated ginsenosides from ginseng root are less active and less absorbable [50,52,53]. Similarly, they are used to convert the bioactive isoflavonoid-glucosides from soybean and other leguminous plants into aglycones with higher bioavailability and pharmaceutical activity $[44,50,54]$. Moreover, $\beta$-glucosidases can perform reverse hydrolysis or transglycosylation catalytic pathways for the formation of new glycosidic bonds, 
a property that makes them interesting for the production of functional compounds, and nutraceutical and pharmaceutical products [44]. For example gentibiose, a product of transglycosylation by $\beta$-glucanases, can be used as a prebiotic food additive [50]. These kinds of enzymatic transformations constitute important alternatives to chemical synthesis involving the use of organic solvents [55]. In this regard, the valorization of spent coffee grounds to produce isoflavone glycosides has also been proposed [54].

\section{Metagenomics for the Search of Novel Cellulases}

The metabolism of thermophiles holds great potential for several industrial applications, but due to the difficulty of growing extremophiles in the laboratory, culture-independent techniques constitute instrumental methods to have access to it. The use of metagenomics, the study of whole communities' genomes, has proven to be a useful tool for the discovery of novel cellulases, both in the functional and the sequence-based approaches $[10,11]$. Several studies had found cellulases in a wide variety of natural thermophilic environments, such as hydrothermal vents [56,57], continental geothermal pools and hotsprings [58,59], and man-made environments like vermicompost [60], compost [37,61,62], and biogas digesters [63]. Nevertheless, high-temperature acting enzymes have also been found by metagenomics on moderate-temperature samples like soils $[40,64,65]$ and aquatic environments [66], and in microorganisms associated with animals like microbial communities in rabbit cecum [67], ruminants rumen [36,68,69], earthworm casts [70], and thermite guts [71,72].

The main limiting factor for the discovery of new thermophile cellulases by functional metagenomics is the host organism used for the metagenomic libraries, typically the mesophilic bacterium E. coli, which may have a limited or biased expression of gene products from thermophiles [3]. One of the proposed solutions for this problem is the use of an alternative thermophilic host for the metagenomic libraries that would increase the hit detection rate for cellulases [11]. It should also be noted that bacteria hosts are not able to express fungal enzymes, as the promoter and intron regions are not recognized [3]. Lastly, the discovery of novel cellobiohydrolases through metagenomics is limited due to the lack of specific substrates other than AVICEL that can discriminate between true cellobiohydrolases and other celullases, as AVICEL has the requirement of a synergy between an endoglucanase and an exoglucanase for detection of activity [3]. The other metagenomic approach, an analysis of the whole metagenome sequencing data, can overcome the problems that arise in the expression-based approach. Regardless, the discovery of gene products with novel characteristics is hindered due to the need of high amino acid homology with already known enzymes, and before assigning putative proteins a function, activities should be verified [11].

\section{Thermophile Cellulases Characterized}

Tables 1-5 list, respectively, endoglucanases, exoglucanases acting on non-reducing ends, exoglucanases acting on reducing ends, cellodextrinases and $\beta$-glucanases that can be considered thermophilic (optimum temperature at $50{ }^{\circ} \mathrm{C}$ or higher), and other key parameters for their industrial application, namely, $\mathrm{pH}$ optimum and temperature stability, their classification according to the CAZY database, and their source organism.

Table 1. Characterized endoglucanases (EC 3.2.1.4) from thermophiles. NM: not measured.

\begin{tabular}{|c|c|c|c|c|c|c|}
\hline Enzyme & $\begin{array}{c}\text { GH Family } \\
\text { Domains }\end{array}$ & $\begin{array}{c}\text { Optimum } \\
\text { Temperature }\end{array}$ & $\begin{array}{c}\text { Optimum } \\
\mathrm{pH}\end{array}$ & $\begin{array}{c}\text { Temperature } \\
\text { Stability }^{1}\end{array}$ & Source & Reference \\
\hline EGPh & 5 & $>97^{\circ} \mathrm{C}$ & $5.4-6.0$ & $80 \% ; 97^{\circ} \mathrm{C} ; 3 \mathrm{~h}$ & $\begin{array}{c}\text { Archaea } \\
\text { (Pyrococcus horikoshii) }\end{array}$ & [46] \\
\hline EG1 & 5 & $83^{\circ} \mathrm{C}$ & 5.0 & $20 \% ; 90{ }^{\circ} \mathrm{C} ; 2 \mathrm{~h}$ & $\begin{array}{c}\text { Bacteria } \\
\text { (Acidothermus cellolyticus) }\end{array}$ & [73] \\
\hline
\end{tabular}


Table 1. Cont.

\begin{tabular}{|c|c|c|c|c|c|c|}
\hline Enzyme & $\begin{array}{l}\text { GH Family } \\
\text { Domains }\end{array}$ & $\begin{array}{l}\text { Optimum } \\
\text { Temperature }\end{array}$ & $\begin{array}{c}\text { Optimum } \\
\mathrm{pH}\end{array}$ & $\begin{array}{l}\text { Temperature } \\
\text { Stability }\end{array}$ & Source & Reference \\
\hline EgIII & 5 & $50^{\circ} \mathrm{C}$ & 6.0 & NM & $\begin{array}{c}\text { Bacteria } \\
\text { (Bacillus amyloliquefaciens) }\end{array}$ & [74] \\
\hline EG & 5 & $65^{\circ} \mathrm{C}$ & 6.0 & $\begin{array}{c}72 \% ; 55^{\circ} \mathrm{C} ; 42 \mathrm{~h} \\
50 \% ; 65^{\circ} \mathrm{C} ; 12 \mathrm{~min}\end{array}$ & $\begin{array}{c}\text { Bacteria } \\
\text { (Bacillus licheniformis) }\end{array}$ & [75] \\
\hline CelA & 5 & $60^{\circ} \mathrm{C}$ & 8.0 & $30 \% ; 70{ }^{\circ} \mathrm{C} ; 1 \mathrm{~h}$ & Bacteria (Bacillus subtilis) & [76] \\
\hline TmCel5A & 5 & $80^{\circ} \mathrm{C}$ & 6.0 & $50 \% ; 80^{\circ} \mathrm{C} ; 18 \mathrm{~h}$ & $\begin{array}{c}\text { Bacteria } \\
\text { (Thermotoga maritima) }\end{array}$ & [77] \\
\hline EglA & 5 & $57^{\circ} \mathrm{C}$ & 4.0 & NM & $\begin{array}{c}\text { Fungi } \\
\text { (Aspergillus nidulans) }\end{array}$ & [78] \\
\hline EglB & 5 & $52^{\circ} \mathrm{C}$ & 4.0 & $\mathrm{NM}$ & $\begin{array}{c}\text { Fungi } \\
\text { (Aspergillus nidulans) }\end{array}$ & [78] \\
\hline EBI-244 & 5 & $109^{\circ} \mathrm{C}$ & 5.5 & $\begin{array}{l}50 \% ; 100{ }^{\circ} \mathrm{C} ; 4.5 \mathrm{~h} \\
50 \% ; 105^{\circ} \mathrm{C} ; 0.57 \mathrm{~h} \\
108{ }^{\circ} \mathrm{C} ; 50 \% ; 0.17 \mathrm{~h}\end{array}$ & $\begin{array}{c}\text { Uncultured Archaea } \\
\text { (Continental geothermal } \\
\text { pool enrichment) }\end{array}$ & [58] \\
\hline CelE1 & 5 & $50{ }^{\circ} \mathrm{C}$ & 7.0 & NM & $\begin{array}{c}\text { Uncultured organism } \\
\text { (Sugarcane field soil } \\
\text { metagenome) }\end{array}$ & [64] \\
\hline CelA10 & 5 & $55^{\circ} \mathrm{C}$ & 7.5 & NM & $\begin{array}{c}\text { Uncultured organism } \\
\text { (Aquatic community and } \\
\text { soil sample) }\end{array}$ & [66] \\
\hline CelA24 & 5 & $55^{\circ} \mathrm{C}$ & 7.0 & $\mathrm{NM}$ & $\begin{array}{c}\text { Uncultured organism } \\
\text { (Aquatic community and } \\
\text { soil sample) }\end{array}$ & [66] \\
\hline cMGL504 & 5 & $50{ }^{\circ} \mathrm{C}$ & 5.5 & NM & $\begin{array}{l}\text { Uncultured organism } \\
\text { (Vermicompost sample) }\end{array}$ & [60] \\
\hline Cel5G & 5 & $50^{\circ} \mathrm{C}$ & 4.8 & $>90 \% ; 50{ }^{\circ} \mathrm{C} ; 30 \mathrm{~min}$ & $\begin{array}{l}\text { Uncultured organism } \\
\text { (Soil metagenome) }\end{array}$ & [65] \\
\hline En1 & 5 & $55^{\circ} \mathrm{C}$ & 5.5 & $\begin{array}{c}87 \% ; 45^{\circ} \mathrm{C} ; 16 \mathrm{~h} \\
67 \% ; 50{ }^{\circ} \mathrm{C} ; 6 \mathrm{~h} \\
42 \% ; 55^{\circ} \mathrm{C} ; 30 \mathrm{~min}\end{array}$ & $\begin{array}{l}\text { Uncultured organism } \\
\text { (Biogas digester } \\
\text { metagenome) }\end{array}$ & [63] \\
\hline $\mathrm{RC} 1$ & 5 & $55^{\circ} \mathrm{C}$ & $6.0-6.5$ & $>90 \% ; 50{ }^{\circ} \mathrm{C} ; 30 \mathrm{~min}$ & $\begin{array}{l}\text { Uncultured organism } \\
\text { (Rabbit cecum } \\
\text { metagenome) }\end{array}$ & [67] \\
\hline RC3 & 5 & $50^{\circ} \mathrm{C}$ & $6.0-7.0$ & $\mathrm{NM}$ & $\begin{array}{l}\text { Uncultured organism } \\
\text { (Rabbit cecum } \\
\text { metagenome) }\end{array}$ & [67] \\
\hline RC5 & 5 & $50^{\circ} \mathrm{C}$ & $6.5-7.0$ & NM & $\begin{array}{l}\text { Uncultured organism } \\
\text { (Rabbit cecum } \\
\text { metagenome) }\end{array}$ & [67] \\
\hline CelL & 6 & $50^{\circ} \mathrm{C}$ & 5.0 & $50 \% ; 50{ }^{\circ} \mathrm{C} ; 12 \mathrm{~min}$ & $\begin{array}{c}\text { Bacteria } \\
\text { (Cellulosimicrobium funkei) }\end{array}$ & [22] \\
\hline Cel6A & 6 & $58^{\circ} \mathrm{C}$ & 6.5 & $>80 \% ; 56{ }^{\circ} \mathrm{C} ; 18 \mathrm{~h}$ & $\begin{array}{c}\text { Bacteria } \\
\text { (Thermobifida fusca) }\end{array}$ & [79] \\
\hline ThCel6A & 6 & $55^{\circ} \mathrm{C}$ & 8.5 & $58 \% ; 90{ }^{\circ} \mathrm{C} ; 1 \mathrm{~h}$ & $\begin{array}{c}\text { Bacteria } \\
\text { (Thermobifida halotolerans) }\end{array}$ & {$[80]$} \\
\hline Cel6A & 6 & $50-55^{\circ} \mathrm{C}$ & 5.5 & $\mathrm{NM}$ & $\begin{array}{c}\text { Bacteria } \\
\text { (Xylanimicrobium } \\
\text { pachnodae })\end{array}$ & [81] \\
\hline HiCel6C & 6 & $70{ }^{\circ} \mathrm{C}$ & 6.5 & $>90 \% ; 60{ }^{\circ} \mathrm{C} ; 1 \mathrm{~h}$ & $\begin{array}{c}\text { Fungi } \\
\text { (Humicola insolens) }\end{array}$ & [82] \\
\hline Cel6A & 6 & $50{ }^{\circ} \mathrm{C}$ & 4.8 & $\begin{array}{l}>90 \% ; 45^{\circ} \mathrm{C} ; 24 \mathrm{~h} \\
92 \% ; 50{ }^{\circ} \mathrm{C} ; 5 \mathrm{~h}\end{array}$ & Fungi (Orpinomyces sp.) & [83] \\
\hline $\mathrm{C} 1$ & 6 & $50{ }^{\circ} \mathrm{C}$ & 6.0 & $100 \% ; 60^{\circ} \mathrm{C} ; 30 \mathrm{~min}$ & $\begin{array}{l}\text { Uncultured organism } \\
\text { (Compost metagenome) }\end{array}$ & {$[61]$} \\
\hline pre-LC-CelB & 6 & NM & NM & $\mathrm{NM}$ & $\begin{array}{l}\text { Uncultured organism } \\
\text { (Compost metagenome) }\end{array}$ & {$[62]$} \\
\hline pre-LC-CelJ & 6 & $\mathrm{NM}$ & NM & NM & $\begin{array}{l}\text { Uncultured organism } \\
\text { (Compost metagenome) }\end{array}$ & {$[62]$} \\
\hline EGI & 7 & $55-60{ }^{\circ} \mathrm{C}$ & 5.0 & $>80 \% ; 60{ }^{\circ} \mathrm{C} ; 10 \mathrm{~min}$ & $\begin{array}{c}\text { Fungi } \\
\text { (Humicola grisea var. } \\
\text { thermoidea) }\end{array}$ & [84] \\
\hline Cel7B & 7 & $60^{\circ} \mathrm{C}$ & 4.0 & $>90 \% ; 60{ }^{\circ} \mathrm{C} ; 1 \mathrm{~h}$ & $\begin{array}{c}\text { Fungi } \\
\text { (Penicillium decumbens) }\end{array}$ & [85] \\
\hline Cel7A & 7 & $60^{\circ} \mathrm{C}$ & 5.0 & $\begin{array}{l}100 \% ; 60{ }^{\circ} \mathrm{C} ; 1 \mathrm{~h} \\
16.1 \% ; 70{ }^{\circ} \mathrm{C} ; 1 \mathrm{~h}\end{array}$ & $\begin{array}{c}\text { Fungi } \\
\text { (Neosartorya fischeri) }\end{array}$ & [33] \\
\hline MtEG7 & 7 & $60^{\circ} \mathrm{C}$ & 5.0 & $\begin{array}{l}50 \% ; 70{ }^{\circ} \mathrm{C} ; 9.96 \mathrm{~h} \\
50 \% ; 80^{\circ} \mathrm{C} ; 6.5 \mathrm{~h}\end{array}$ & $\begin{array}{c}\text { Fungi } \\
\text { (Myceliophthora } \\
\text { thermophila) }\end{array}$ & [31] \\
\hline
\end{tabular}


Table 1. Cont.

\begin{tabular}{|c|c|c|c|c|c|c|}
\hline Enzyme & $\begin{array}{l}\text { GH Family } \\
\text { Domains }\end{array}$ & $\begin{array}{l}\text { Optimum } \\
\text { Temperature }\end{array}$ & $\begin{array}{l}\text { Optimum } \\
\text { pH }\end{array}$ & $\begin{array}{l}\text { Temperature } \\
\text { Stability }\end{array}$ & Source & Reference \\
\hline EGL1 & 7 & $62{ }^{\circ} \mathrm{C}$ & 4.8 & NM & $\begin{array}{c}\text { Fungi } \\
\text { (Trichoderma } \\
\text { longibrachiatum) }\end{array}$ & [51] \\
\hline MaCel7A & 7 & $65-70^{\circ} \mathrm{C}$ & 6.0 & NM & $\begin{array}{c}\text { Fungi } \\
\text { (Melanocarpus albomyces) }\end{array}$ & [86] \\
\hline CelC & 8 & $50^{\circ} \mathrm{C}$ & 6.5 & NM & $\begin{array}{c}\text { Bacteria } \\
\text { (Salmonella typhimurium) }\end{array}$ & [87] \\
\hline Cel8Y & 8 & $80^{\circ} \mathrm{C}$ & 7.0 & $\begin{array}{l}50 \% ; 90^{\circ} \mathrm{C} ; 4 \mathrm{~h} \\
50 \% ; 100^{\circ} \mathrm{C} ; 2 \mathrm{~h}\end{array}$ & $\begin{array}{c}\text { Bacteria } \\
\text { (Aquifex geolicus) }\end{array}$ & [88] \\
\hline Egl-257 & 8 & $55^{\circ} \mathrm{C}$ & 8.5 & $\begin{array}{l}100 \% ; 50{ }^{\circ} \mathrm{C} ; 15 \mathrm{~min} \\
>50 \% ; 60^{\circ} \mathrm{C} ; 15 \mathrm{~min}\end{array}$ & $\begin{array}{c}\text { Bacteria } \\
\text { (Bacillus circulans) }\end{array}$ & [89] \\
\hline CenC & 9 & $70^{\circ} \mathrm{C}$ & 6.0 & $\begin{array}{l}100 \% ; 60{ }^{\circ} \mathrm{C} ; 2 \mathrm{~h} \\
60 \% ; 70{ }^{\circ} \mathrm{C} ; 1 \mathrm{~h}\end{array}$ & $\begin{array}{c}\text { Bacteria } \\
\text { (Clostridium thermocellum) }\end{array}$ & [90] \\
\hline CelA & $\begin{array}{c}9 \\
\text { (endoglucanase) } \\
\text { and } 48 \\
\text { (cellobiohydrolase) }\end{array}$ & $\begin{array}{l}95^{\circ} \mathrm{C} \\
\text { (endoglucanase) } \\
\text { and } 85^{\circ} \mathrm{C} \\
\text { (cellobiohydrolase) }\end{array}$ & $5.0-6.0$ & $\begin{array}{l}50 \% ; 95^{\circ} \mathrm{C} ; 40 \mathrm{~min} \\
\text { (endoglucanase) } \\
100 \% ; 85^{\circ} \mathrm{C} ; 4 \mathrm{~h} \\
\text { (cellobiohydrolase) }\end{array}$ & $\begin{array}{c}\text { Bacteria } \\
\text { (Caldicellulosiruptor bescii) }\end{array}$ & [91] \\
\hline Cel9A & 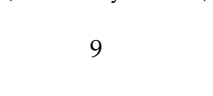 & $65^{\circ} \mathrm{C}$ & 6.5 & $\mathrm{NM}$ & $\begin{array}{c}\text { Bacteria } \\
\text { (Lachnoclostridium } \\
\text { phytofermentans) }\end{array}$ & [92] \\
\hline CelA20 & 9 & $55^{\circ} \mathrm{C}$ & 5.0 & NM & $\begin{array}{c}\text { Uncultured organism } \\
\text { (Aquatic community and } \\
\text { soil metagenome) }\end{array}$ & [66] \\
\hline AcCel12B & 12 & $75^{\circ} \mathrm{C}$ & 4.5 & $\begin{array}{l}50 \% ; 60{ }^{\circ} \mathrm{C} ; 90 \mathrm{~h} \\
50 \% ; 65^{\circ} \mathrm{C} ; 55 \mathrm{~h} \\
50 \% ; 70{ }^{\circ} \mathrm{C} ; 2 \mathrm{~h}\end{array}$ & $\begin{array}{l}\text { Bacteria } \\
\text { (Acidothermus } \\
\text { cellulolyticus) }\end{array}$ & [35] \\
\hline CelA & 12 & $95^{\circ} \mathrm{C}$ & 6.0 & $\mathrm{NM}$ & $\begin{array}{c}\text { Bacteria } \\
\text { (Thermotoga neapolitana) }\end{array}$ & [8] \\
\hline CelB & 12 & $106^{\circ} \mathrm{C}$ & $6.0-6.6$ & $\begin{array}{c}50 \% ; 106{ }^{\circ} \mathrm{C} ; 130 \\
\min \\
50 \% ; 110^{\circ} \mathrm{C} ; 26 \mathrm{~min} \\
73 \% ; 100{ }^{\circ} \mathrm{C} ; 4 \mathrm{~h}\end{array}$ & $\begin{array}{c}\text { Bacteria } \\
\text { (Thermotoga neapolitana) }\end{array}$ & [8] \\
\hline TmCel12A & 12 & $90^{\circ} \mathrm{C}$ & 7.0 & $\begin{array}{c}>40 \% ; 85^{\circ} \mathrm{C} ; 48 \mathrm{~h} \\
50 \% ; 90{ }^{\circ} \mathrm{C} ; 3 \mathrm{~h}\end{array}$ & $\begin{array}{c}\text { Bacteria } \\
\text { (Thermotoga maritima) }\end{array}$ & [93] \\
\hline TmCel12B & 12 & $85^{\circ} \mathrm{C}$ & 6.0 & $50 \% ; 90{ }^{\circ} \mathrm{C} ; 9 \mathrm{~h}$ & $\begin{array}{c}\text { Bacteria } \\
\text { (Thermotoga maritima) }\end{array}$ & [93] \\
\hline CelA & 12 & $>100^{\circ} \mathrm{C}$ & $6.0-7.0$ & $45 \% ; 90{ }^{\circ} \mathrm{C} ; 8 \mathrm{~h}$ & $\begin{array}{c}\text { Bacteria } \\
\text { (Rhodothermus marinus) }\end{array}$ & [23] \\
\hline EglA & 12 & $100^{\circ} \mathrm{C}$ & 6.0 & $50 \% ; 95^{\circ} \mathrm{C} ; 40 \mathrm{~h}$ & $\begin{array}{c}\text { Archaea } \\
\text { (Pyrococcus furiosus) }\end{array}$ & [94] \\
\hline SSO1949 & 12 & $80^{\circ} \mathrm{C}$ & 1.8 & $50 \% ; 80{ }^{\circ} \mathrm{C} ; 8 \mathrm{~h}$ & $\begin{array}{c}\text { Archeaea } \\
\text { (Sulfolobus solfataricus) }\end{array}$ & [95] \\
\hline SSO1354 & 12 & $90^{\circ} \mathrm{C}$ & 4.0 & $50 \% ; 90{ }^{\circ} \mathrm{C} ; 180 \mathrm{~min}$ & $\begin{array}{c}\text { Archaea } \\
\text { (Sulfolobus solfataricus) }\end{array}$ & [39] \\
\hline EglS & 12 & $65^{\circ} \mathrm{C}$ & 6.0 & $>40 \% ; 60{ }^{\circ} \mathrm{C} ; 30 \mathrm{~min}$ & $\begin{array}{c}\text { Bacteria } \\
\text { (Streptomyces rochei) }\end{array}$ & [96] \\
\hline Cel12A & 12 & $50^{\circ} \mathrm{C}$ & 5.0 & $\mathrm{NM}$ & $\begin{array}{c}\text { Fungi } \\
\text { (Trichoderma reseei) }\end{array}$ & [97] \\
\hline EG & 12 & $70^{\circ} \mathrm{C}$ & 3.5 & $\begin{array}{l}50 \% ; 70{ }^{\circ} \mathrm{C} ; 3 \mathrm{~h} \\
50 \% ; 80^{\circ} \mathrm{C} ; 1 \mathrm{~h}\end{array}$ & $\begin{array}{c}\text { Fungi } \\
\text { (Aspergillus niger) }\end{array}$ & [27] \\
\hline Pre-LC-CelA & 12 & $90^{\circ} \mathrm{C}$ & $5.0-9.0$ & $100 \% ; 90{ }^{\circ} \mathrm{C} ; 30 \mathrm{~min}$ & $\begin{array}{l}\text { Uncultured organism } \\
\text { (Compost metagenome) }\end{array}$ & [62] \\
\hline Pre-LC-CelD & 12 & NM & NM & $\mathrm{NM}$ & $\begin{array}{l}\text { Uncultured organism } \\
\text { (Compost metagenome) }\end{array}$ & [62] \\
\hline Pre-LC-CelE & 12 & $\mathrm{NM}$ & NM & $\mathrm{NM}$ & $\begin{array}{l}\text { Uncultured organism } \\
\text { (Compost metagenome) }\end{array}$ & [62] \\
\hline Cel12E & 12 & $92{ }^{\circ} \mathrm{C}$ & 5.5 & $>80 \% ; 80{ }^{\circ} \mathrm{C} ; 4.5 \mathrm{~h}$ & $\begin{array}{l}\text { Uncharacterized archeon } \\
\quad \text { (deep sea vents } \\
\text { metagenome enrichment) }\end{array}$ & [57] \\
\hline GH44EG & 44 & $55^{\circ} \mathrm{C}$ & 5.0 & $\mathrm{NM}$ & $\begin{array}{c}\text { Bacteria } \\
\text { (Clostridium } \\
\text { acetobutylicum })\end{array}$ & [98] \\
\hline CelA & 44 & $60{ }^{\circ} \mathrm{C}$ & $5.0-8.5$ & $50 \% ; 60{ }^{\circ} \mathrm{C} ; 70 \mathrm{~min}$ & $\begin{array}{c}\text { Bacteria } \\
\text { (Paenibacillus lautus) }\end{array}$ & [99] \\
\hline CelJ & 44 & $70^{\circ} \mathrm{C}$ & 6.5 & $>90 \% ; 80^{\circ} \mathrm{C} ; 10 \mathrm{~min}$ & $\begin{array}{c}\text { Bacteria } \\
\text { (Ruminiclostridium } \\
\text { thermocellum) }\end{array}$ & [100] \\
\hline
\end{tabular}


Table 1. Cont.

\begin{tabular}{|c|c|c|c|c|c|c|}
\hline Enzyme & $\begin{array}{l}\text { GH Family } \\
\text { Domains }\end{array}$ & $\begin{array}{l}\text { Optimum } \\
\text { Temperature }\end{array}$ & $\begin{array}{c}\text { Optimum } \\
\mathrm{pH}\end{array}$ & $\begin{array}{l}\text { Temperature } \\
\text { Stability }\end{array}$ & Source & Reference \\
\hline pre-LC-CelH & 44 & NM & NM & NM & $\begin{array}{l}\text { Uncultured organism } \\
\text { (Compost metagenome) }\end{array}$ & [62] \\
\hline Cel45A & 45 & $60^{\circ} \mathrm{C}$ & 5.0 & NM & $\begin{array}{c}\text { Fungi } \\
\text { (Trichoderma reseei) }\end{array}$ & [97] \\
\hline PpCel45A & 45 & $65^{\circ} \mathrm{C}$ & 4.8 & $\begin{array}{l}70 \% ; 65^{\circ} \mathrm{C} ; 48 \mathrm{~h} \\
60 \% ; 80^{\circ} \mathrm{C} ; 4 \mathrm{~h}\end{array}$ & $\begin{array}{c}\text { Fungi } \\
\text { (Picchia pastoris) }\end{array}$ & [5] \\
\hline STCE1 & 45 & $60^{\circ} \mathrm{C}$ & 6.0 & NM & $\begin{array}{c}\text { Fungi } \\
\text { (Staphylotrichum } \\
\text { coccosporum) }\end{array}$ & [101] \\
\hline BCC 18080 & 45 & $70^{\circ} \mathrm{C}$ & 6.0 & $\begin{array}{l}>70 \% ; 70{ }^{\circ} \mathrm{C} ; 2 \mathrm{~h} \\
>50 \% ; 70{ }^{\circ} \mathrm{C} ; 4 \mathrm{~h}\end{array}$ & $\begin{array}{c}\text { Fungi } \\
\text { (Syncephalastrum } \\
\text { racemosum })\end{array}$ & [102] \\
\hline BCE1 & 45 & $55^{\circ} \mathrm{C}$ & 4.5 & NM & $\begin{array}{c}\text { Fungi } \\
\text { (Beltraniella portoricensis) }\end{array}$ & [103] \\
\hline MaCel45A & 45 & $70^{\circ} \mathrm{C}$ & 7.0 & NM & $\begin{array}{c}\text { Fungi } \\
\text { (Melanocarpus albomyces) } \\
\text { Bacteria }\end{array}$ & [86] \\
\hline CelB & 51 & $80^{\circ} \mathrm{C}$ & 4.0 & $60 \% ; 80^{\circ} \mathrm{C} ; 1 \mathrm{~h}$ & $\begin{array}{c}\text { (Alicyclobacillus } \\
\text { acidocaldarius) }\end{array}$ & [104] \\
\hline CelA4 & 51 & $65^{\circ} \mathrm{C}$ & 2.6 & $>85 \% ; 60{ }^{\circ} \mathrm{C} ; 1 \mathrm{~h}$ & $\begin{array}{c}\text { Bacteria } \\
\text { (Alicyclobacillus sp. A4) }\end{array}$ & [47] \\
\hline CelVA & 51 & $80^{\circ} \mathrm{C}$ & $3.6-4.5$ & $70 \% ; 70{ }^{\circ} \mathrm{C} ; 2 \mathrm{~h}$ & $\begin{array}{c}\text { Bacteria } \\
\text { (Alicyclobacillus vulcanalis) }\end{array}$ & [45] \\
\hline pre-LC-CelC & 51 & NM & NM & NM & $\begin{array}{l}\text { Uncultured organism } \\
\text { (Compost metagenome) }\end{array}$ & [62] \\
\hline TmCel74 & 74 & $90^{\circ} \mathrm{C}$ & 6.0 & $50 \% ; 90^{\circ} \mathrm{C} ; 5 \mathrm{~h}$ & $\begin{array}{c}\text { Bacteria } \\
\text { (Thermotoga maritima) }\end{array}$ & [15] \\
\hline CtCel124 & 124 & NM & NM & $\mathrm{NM}$ & $\begin{array}{c}\text { Bacteria } \\
\text { (Ruminiclostridium } \\
\text { thermocellum) }\end{array}$ & [105] \\
\hline
\end{tabular}

${ }^{1}$ Temperature stability is given as a percentage of activity (residual activity) after treatment at the specified temperature and time compared to the untreated enzyme.

Table 2. Characterized exoglucanases (1,4- $\beta$-cellobiosidase) acting on non-reducing ends from thermophiles (EC 3.2.1.91). NM: not measured.

\begin{tabular}{|c|c|c|c|c|c|c|}
\hline Enzyme & $\begin{array}{l}\text { GH Family } \\
\text { Domains }\end{array}$ & $\begin{array}{l}\text { Optimum } \\
\text { Temperature }\end{array}$ & $\begin{array}{l}\text { Optimum } \\
\text { pH }\end{array}$ & $\begin{array}{l}\text { Temperature } \\
\text { Stability }{ }^{1}\end{array}$ & Source & Reference \\
\hline CBHII & 6 & $60^{\circ} \mathrm{C}$ & 4.0 & $30 \% ; 100{ }^{\circ} \mathrm{C} ; 10 \mathrm{~min}$ & $\begin{array}{c}\text { Bacteria } \\
\text { (Streptomyces sp. M23) }\end{array}$ & [106] \\
\hline Cel6B & 6 & NM & $7.0-8.0$ & $100 \% ; 55^{\circ} \mathrm{C} ; 16 \mathrm{~h}$ & $\begin{array}{c}\text { Bacteria } \\
\text { (Thermobifida fusca) }\end{array}$ & [107] \\
\hline CBHII & 6 & $57^{\circ} \mathrm{C}$ & 5.5 & NM & $\begin{array}{c}\text { Fungi } \\
\text { (Aspergillus nidulans) }\end{array}$ & [78] \\
\hline Cel6A & 6 & $50^{\circ} \mathrm{C}$ & 4.0 & $50 \% ; 70^{\circ} \mathrm{C} ; 30 \mathrm{~min}$ & $\begin{array}{c}\text { Fungi } \\
\text { (Chaetomium thermophilum) }\end{array}$ & [108] \\
\hline $\begin{array}{c}\text { CBHII } \\
\text { (Cel6A) }\end{array}$ & 6 & $60^{\circ} \mathrm{C}$ & $5.0-5.5$ & $>90 \% ; 50{ }^{\circ} \mathrm{C} ; 5 \mathrm{~h}$ & $\begin{array}{c}\text { Fungi } \\
\text { (Chrysosporium lucknowense) }\end{array}$ & [109] \\
\hline HiCel6A & 6 & $60-65^{\circ} \mathrm{C}$ & NM & $50 \% ; 75^{\circ} \mathrm{C} ;<25 \mathrm{~min}$ & $\begin{array}{c}\text { Fungi } \\
\text { (Humicola insolens) }\end{array}$ & [26] \\
\hline Ex-4 & 6 & $50^{\circ} \mathrm{C}$ & 5.0 & $80 \% ; 60^{\circ} \mathrm{C} ; 60 \mathrm{~min}$ & $\begin{array}{c}\text { Fungi } \\
\text { (Irpex Lacteus) }\end{array}$ & [110] \\
\hline PoCel6A & 6 & $50^{\circ} \mathrm{C}$ & 5.0 & $\begin{array}{l}90 \% ; 50{ }^{\circ} \mathrm{C} ; 2 \mathrm{~h} \\
80 \% ; 60{ }^{\circ} \mathrm{C} ; 4 \mathrm{~h}\end{array}$ & $\begin{array}{c}\text { Fungi } \\
\text { (Penicillium oxalicum) }\end{array}$ & [111] \\
\hline PaCel6A & 6 & $55^{\circ} \mathrm{C}$ & $5.0-9.0$ & $\begin{array}{l}100 \% ; 35^{\circ} \mathrm{C} ; 24 \mathrm{~h} \\
>20 \% ; 45^{\circ} \mathrm{C} ; 24 \mathrm{~h}\end{array}$ & $\begin{array}{c}\text { Fungi } \\
\text { (Podospora anserina) }\end{array}$ & [19] \\
\hline CBHII & 6 & $70^{\circ} \mathrm{C}$ & 5.0 & NM & $\begin{array}{c}\text { Fungi } \\
\text { (Trichoderma viride) }\end{array}$ & [112] \\
\hline G10-6 & 6 & $55^{\circ} \mathrm{C}$ & 9.5 & NM & $\begin{array}{c}\text { Uncultured organism } \\
\text { (Eathworm casts metagenome) }\end{array}$ & [70] \\
\hline Cbh9A & 9 & $60^{\circ} \mathrm{C}$ & 6.5 & NM & $\begin{array}{c}\text { Bacteria } \\
\text { (Ruminiclostridium } \\
\text { thermocellum })\end{array}$ & [113] \\
\hline Cel9K & 9 & $65^{\circ} \mathrm{C}$ & 6.0 & $97 \% ; 60^{\circ} \mathrm{C} ; 200 \mathrm{~h}$ & $\begin{array}{c}\text { Bacteria } \\
\text { (Ruminiclostridium } \\
\text { thermocellum) }\end{array}$ & [114] \\
\hline
\end{tabular}

\footnotetext{
${ }^{1}$ Temperature stability is given as a percentage of activity (residual activity) after treatment at the specified temperature and time compared to the untreated enzyme.
} 
Table 3. Characterized exoglucanases (1,4- $\beta$-cellobiosidase) acting on reducing ends from thermophiles (EC 3.2.1.176). NM: not measured.

\begin{tabular}{|c|c|c|c|c|c|c|}
\hline Enzyme & $\begin{array}{l}\text { GH Family } \\
\text { Domains }\end{array}$ & $\begin{array}{l}\text { Optimum } \\
\text { Temperature }\end{array}$ & $\begin{array}{l}\text { Optimum } \\
\text { pH }\end{array}$ & $\begin{array}{l}\text { Temperature } \\
\text { Stability }^{1}\end{array}$ & Source & Reference \\
\hline CelO & 5 & $65^{\circ} \mathrm{C}$ & 6.6 & NM & $\begin{array}{c}\text { Bacteria } \\
\text { (Ruminiclostridium } \\
\text { thermocellum) }\end{array}$ & [115] \\
\hline AtCel7A & 7 & $60^{\circ} \mathrm{C}$ & 5.0 & NM & $\begin{array}{c}\text { Fungi } \\
\text { (Acremonium thermophilum) }\end{array}$ & [28] \\
\hline $\mathrm{CBHI}$ & 7 & $60^{\circ} \mathrm{C}$ & 3.0 & NM & $\begin{array}{c}\text { Fungi } \\
\text { (Aspergillus aculeatus) }\end{array}$ & [116] \\
\hline $\mathrm{CBHI}$ & 7 & $55^{\circ} \mathrm{C}$ & NM & NM & $\begin{array}{c}\text { Fungi } \\
\text { (Aspergillus fumigatus) }\end{array}$ & [117] \\
\hline CtCel7A & 7 & $65^{\circ} \mathrm{C}$ & 4.0 & $\mathrm{NM}$ & $\begin{array}{c}\text { Fungi } \\
\text { (Chaetomium thermophilum) }\end{array}$ & [28] \\
\hline $\mathrm{CBH} 3$ & 7 & $65^{\circ} \mathrm{C}$ & 5.0 & $\begin{array}{c}50 \% ; 70^{\circ} \mathrm{C} ; 1 \mathrm{~h} \\
20 \% ; 80^{\circ} \mathrm{C} ; 20 \mathrm{~min}\end{array}$ & $\begin{array}{c}\text { Fungi } \\
\text { (Chaetomium thermophilum) }\end{array}$ & [118] \\
\hline DpuCel7A & 7 & $55^{\circ} \mathrm{C}$ & 5.0 & $\mathrm{NM}$ & $\begin{array}{c}\text { Metazoa } \\
\text { (Dictyostelium purpureum) }\end{array}$ & [119] \\
\hline $\mathrm{CBHI}$ & 7 & $60^{\circ} \mathrm{C}$ & 5.0 & $\begin{array}{c}>90 \% ; 55^{\circ} \mathrm{C} ; 10 \\
\min \end{array}$ & $\begin{array}{c}\text { Fungi } \\
\text { (Humicola grisea var. thermoidea) }\end{array}$ & [84] \\
\hline EXO1 & 7 & $65^{\circ} \mathrm{C}$ & 5.0 & $\begin{array}{c}>80 \% ; 65^{\circ} \mathrm{C} ; 10 \\
\min \end{array}$ & $\begin{array}{c}\text { Fungi } \\
\text { (Humicola grisea var. thermoidea) }\end{array}$ & [120] \\
\hline MaCel7B & 7 & $55^{\circ} \mathrm{C}$ & $\mathrm{NM}$ & NM & $\begin{array}{c}\text { Fungi } \\
\text { (Melanocarpus albomyces) }\end{array}$ & [121] \\
\hline TeCel7A & 7 & $65^{\circ} \mathrm{C}$ & $4.0-5.0$ & $50 \% ; 70{ }^{\circ} \mathrm{C} ; 30 \mathrm{~min}$ & $\begin{array}{c}\text { Fungi } \\
\text { (Talaromyces emersonii) }\end{array}$ & [29] \\
\hline Cel7A & 7 & $55^{\circ} \mathrm{C}$ & $3.7-5.2$ & $50 \% ; 50{ }^{\circ} \mathrm{C} ; 2.5 \mathrm{~h}$ & $\begin{array}{c}\text { Fungi } \\
\text { (Penicillium funiculosum) }\end{array}$ & [122] \\
\hline TaCel7A & 7 & $65^{\circ} \mathrm{C}$ & 5.0 & NM & $\begin{array}{c}\text { Fungi } \\
\text { (Thermoascus aurantiacus) }\end{array}$ & [28] \\
\hline ThCBHI & 7 & $50{ }^{\circ} \mathrm{C}$ & 5.0 & NM & $\begin{array}{c}\text { Fungi } \\
\text { (Trichoderma harzianum) }\end{array}$ & [123] \\
\hline $\mathrm{CBHI}$ & 7 & $60^{\circ} \mathrm{C}$ & 5.8 & $\mathrm{NM}$ & $\begin{array}{c}\text { Fungi } \\
\text { (Trichoderma viride) }\end{array}$ & [112] \\
\hline CelA & $\begin{array}{c}9 \\
\text { (endoglucanase) } \\
\text { and } 48 \\
\text { (cellobiohydrolase) }\end{array}$ & $\begin{array}{l}95^{\circ} \mathrm{C} \\
\text { (endoglucanase) } \\
\text { and } 85^{\circ} \mathrm{C} \\
\text { (cellobiohydrolase) }\end{array}$ & $5.0-6.0$ & $\begin{array}{l}50 \% ; 95^{\circ} \mathrm{C} ; 40 \mathrm{~min} \\
\text { (endoglucanase) } \\
100 \% ; 85^{\circ} \mathrm{C} ; 4 \mathrm{~h} \\
\text { (cellobiohydrolase) }\end{array}$ & $\begin{array}{c}\text { Bacteria } \\
\text { (Caldicellulosiruptor bescii) }\end{array}$ & [91] \\
\hline CelY & 48 & $70{ }^{\circ} \mathrm{C}$ & $5.0-6.0$ & NM & $\begin{array}{c}\text { Bacteria } \\
\text { (Clostridium stercorarium) }\end{array}$ & [124] \\
\hline CpCel48 & 48 & $55^{\circ} \mathrm{C}$ & $5.0-6.0$ & $\begin{array}{l}>70 \% ; 50{ }^{\circ} \mathrm{C} ; 30 \\
\min >20 \% ; 55{ }^{\circ} \mathrm{C} ; \\
\quad 30 \mathrm{~min}\end{array}$ & $\begin{array}{c}\text { Bacteria } \\
\text { (Lachnoclostridium } \\
\text { phytofermentans) }\end{array}$ & [125] \\
\hline CelS & 48 & $70{ }^{\circ} \mathrm{C}$ & 5.5 & NM & $\begin{array}{c}\text { Bacteria } \\
\text { (Ruminiclostridium } \\
\text { thermocellum) }\end{array}$ & [126] \\
\hline
\end{tabular}

1 Temperature stability is given as a percentage of activity (residual activity) after treatment at the specified temperature and time compared to the untreated enzyme.

Table 4. Characterized exoglucanases (cellodextrinases) acting on reducing ends from thermophiles (3.2.1.74).

\begin{tabular}{ccccccc}
\hline Enzyme & $\begin{array}{c}\text { GH family } \\
\text { Domains }\end{array}$ & $\begin{array}{c}\text { Optimum } \\
\text { Temperature }\end{array}$ & $\begin{array}{c}\text { Optimum } \\
\mathbf{p H}\end{array}$ & $\begin{array}{c}\text { Temperature } \\
\text { Stability }\end{array}$ & Source & Reference \\
\hline CcGH1 & 1 & $60^{\circ} \mathrm{C}$ & 6.5 & $61 \% ; 50{ }^{\circ} \mathrm{C} ; 30 \mathrm{~min}$ & $\begin{array}{c}\text { Bacteria } \\
(\text { Clostridium Cellulolyticum) } \\
\text { Bacteria }\end{array}$ \\
GghA & 1 & $95{ }^{\circ} \mathrm{C}$ & 6.5 & $\begin{array}{c}85 \% ; 90^{\circ} \mathrm{C} ; 9 \mathrm{~h} \\
88 \% ; 95{ }^{\circ} \mathrm{C} ; 1 \mathrm{~h}\end{array}$ & $\begin{array}{c}\text { [Thermotoga neapolitana) } \\
{[128]}\end{array}$ \\
\hline
\end{tabular}

${ }^{1}$ Temperature stability is given as a percentage of activity (residual activity) after treatment at the specified temperature and time compared to the untreated enzyme. 
Table 5. Characterized $\beta$-glucanases from thermophiles (3.2.1.21). NM: not measured.

\begin{tabular}{|c|c|c|c|c|c|c|}
\hline Enzyme & $\begin{array}{l}\text { GH family } \\
\text { Domains }\end{array}$ & $\begin{array}{l}\text { Optimum } \\
\text { Temperature }\end{array}$ & $\begin{array}{c}\text { Optimum } \\
\mathrm{pH}\end{array}$ & $\begin{array}{l}\text { Temperature } \\
\text { Stability }^{1}\end{array}$ & Source & Reference \\
\hline CelB & 1 & $102-105^{\circ} \mathrm{C}$ & 5.0 & $\begin{array}{l}50 \% ; 100{ }^{\circ} \mathrm{C} ; 85 \mathrm{~h} \\
50 \% ; 110{ }^{\circ} \mathrm{C} ; 13 \mathrm{~h}\end{array}$ & $\begin{array}{c}\text { Arquea } \\
\text { (Pyrococcus furiosus) }\end{array}$ & [129] \\
\hline Tpa-glu & 1 & $75^{\circ} \mathrm{C}$ & 7.5 & $50 \% ; 90^{\circ} \mathrm{C} ; 6 \mathrm{~h}$ & $\begin{array}{c}\text { Arquea } \\
\text { (Thermococcus pacificus) }\end{array}$ & [130] \\
\hline BGPh & 1 & $>100^{\circ} \mathrm{C}$ & 6.0 & $50 \% ; 90{ }^{\circ} \mathrm{C} ; 15 \mathrm{~h}$ & $\begin{array}{c}\text { Arquea } \\
\text { (Pyrococcus horikoshii) }\end{array}$ & [131] \\
\hline LacS & $\begin{array}{c}1 \text { ( } \beta \text {-glucosidase } \\
\text { and } \\
\beta \text {-galactosidase })\end{array}$ & $90^{\circ} \mathrm{C}$ & 6.0 & $90 \% ; 75^{\circ} \mathrm{C} ; 80 \mathrm{~h}$ & $\begin{array}{c}\text { Arquea } \\
\text { (Sulfolobus solfataricus) }\end{array}$ & [132] \\
\hline O08324 & 1 & $78^{\circ} \mathrm{C}$ & $5.0-6.8$ & $50 \% ; 78^{\circ} \mathrm{C} ; 860 \mathrm{~min}$ & $\begin{array}{c}\text { Arquea } \\
\text { (Thermococcus sp.) }\end{array}$ & [133] \\
\hline Bgl1 & 1 & $90^{\circ} \mathrm{C}$ & 6.5 & $\begin{array}{l}67 \% ; 90^{\circ} \mathrm{C} ; 1.5 \mathrm{~h} \\
78 \% ; 50{ }^{\circ} \mathrm{C} ; 24 \mathrm{~h} \\
68 \% ; 60^{\circ} \mathrm{C} ; 24 \mathrm{~h}\end{array}$ & $\begin{array}{l}\text { Uncultured Arquea (hot } \\
\text { spring metagenome) }\end{array}$ & [59] \\
\hline GlyB & $\begin{array}{l}1 \text { (multiple } \\
\text { substrates) }\end{array}$ & $85^{\circ} \mathrm{C}$ & 5.5 & $\begin{array}{l}8 \% ; 80{ }^{\circ} \mathrm{C} ; 10 \mathrm{~min} \\
>70 \% ; 65^{\circ} \mathrm{C} ; 3 \mathrm{~h}\end{array}$ & $\begin{array}{c}\text { Bacteria } \\
\text { (Alicyclobacillus } \\
\text { acidocaldarius) }\end{array}$ & [134] \\
\hline Bglp & 1 & $60^{\circ} \mathrm{C}$ & 7.0 & $50 \% ; 60{ }^{\circ} \mathrm{C} ; 10 \mathrm{~h}$ & $\begin{array}{c}\text { Bacteria } \\
\text { (Anoxybacillus } \\
\text { flavithermus) }\end{array}$ & [135] \\
\hline BglA & 1 & $55^{\circ} \mathrm{C}$ & $6.0-9.0$ & $\begin{array}{l}80 \% ; 50^{\circ} \mathrm{C} ; 15 \mathrm{~min} \\
1 \% ; 60^{\circ} \mathrm{C} ; 15 \mathrm{~min}\end{array}$ & $\begin{array}{l}\text { Bacteria (Bacillus circulans } \\
\text { subsp. Alkalophilus) }\end{array}$ & [136] \\
\hline BhbglA & 1 & $50{ }^{\circ} \mathrm{C}$ & 7.0 & $50 \% ; 50{ }^{\circ} \mathrm{C} ; 30 \mathrm{~min}$ & $\begin{array}{c}\text { Bacteria } \\
\text { (Bacillus halodurans) }\end{array}$ & [137] \\
\hline BglA & 1 & $85^{\circ} \mathrm{C}$ & 6.25 & $\begin{array}{c}50 \% ; 70{ }^{\circ} \mathrm{C} ; 2280 \\
\min \end{array}$ & $\begin{array}{c}\text { Bacteria } \\
\text { (Caldicellulosiruptor } \\
\text { saccharolyticus) }\end{array}$ & [138] \\
\hline $\mathrm{BglA}$ & 1 & $50{ }^{\circ} \mathrm{C}$ & 6.0 & $\mathrm{NM}$ & $\begin{array}{c}\text { Bacteria } \\
\text { (Clostridium cellulovorans) }\end{array}$ & [139] \\
\hline DtGH & 1 & $90^{\circ} \mathrm{C}$ & 7.0 & $\begin{array}{c}50 \% ; 70{ }^{\circ} \mathrm{C} ; 533 \mathrm{~h} \\
50 \% ; 80{ }^{\circ} \mathrm{C} ; 44 \mathrm{~h} \\
50 \% ; 90{ }^{\circ} \mathrm{C} ; 5 \mathrm{~h}\end{array}$ & $\begin{array}{c}\text { Bacteria } \\
\text { (Dictyoglomus } \\
\text { thermophilum) }\end{array}$ & [140] \\
\hline Dtur $\beta$ Glu & 1 & $80^{\circ} \mathrm{C}$ & 5.4 & $70 \% ; 70{ }^{\circ} \mathrm{C} ; 2 \mathrm{~h}$ & $\begin{array}{c}\text { Bacteria } \\
\text { (Dictyoglomus turgidum) }\end{array}$ & {$[44]$} \\
\hline FiBgl1A & 1 & $90^{\circ} \mathrm{C}$ & $6.0-7.0$ & $\begin{array}{l}50 \% ; 90{ }^{\circ} \mathrm{C} 25 \mathrm{~min} \\
50 \% ; 100{ }^{\circ} \mathrm{C} ; 15 \mathrm{~min}\end{array}$ & $\begin{array}{c}\text { Bacteria } \\
\text { (Fervidobacterium } \\
\text { islandicum) }\end{array}$ & [141] \\
\hline BglA & 1 & $60^{\circ} \mathrm{C}$ & 6.5 & $\begin{array}{l}91 \% ; 60{ }^{\circ} \mathrm{C} ; 3 \mathrm{~h} \\
34 \% ; 60{ }^{\circ} \mathrm{C} ; 43 \mathrm{~h}\end{array}$ & $\begin{array}{c}\text { Bacteria } \\
\text { (Ruminiclostridium } \\
\text { thermocellum })\end{array}$ & [142] \\
\hline SdBgl1B & 1 & $50{ }^{\circ} \mathrm{C}$ & $6.0-7.5$ & NM & $\begin{array}{c}\text { Bacteria } \\
\text { (Saccharophagus degradans) }\end{array}$ & [143] \\
\hline Bgl1 & 1 & $50^{\circ} \mathrm{C}$ & $5.1-5.7$ & $60 \% ; 40{ }^{\circ} \mathrm{C} ; 4 \mathrm{~h}$ & $\begin{array}{c}\text { Bacteria } \\
\text { (Sphingomonas } \\
\text { paucimobilis) }\end{array}$ & [144] \\
\hline SGR_2426 & 1 & $69^{\circ} \mathrm{C}$ & 6.9 & $50 \% ; 69^{\circ} \mathrm{C} ; 1.5 \mathrm{~h}$ & $\begin{array}{c}\text { Bacteria } \\
\text { (Streptomyces griseus) } \\
\text { Bacteria }\end{array}$ & [55] \\
\hline $\mathrm{Bgl3}$ & 1 & $50^{\circ} \mathrm{C}$ & 6.5 & $\mathrm{NM}$ & $\begin{array}{c}\text { (Streptomyces sp. strain } \\
\text { QM-B814) }\end{array}$ & [145] \\
\hline CglT & 1 & $75^{\circ} \mathrm{C}$ & 5.5 & $100 \% ; 60{ }^{\circ} \mathrm{C} ; 24 \mathrm{~h}$ & $\begin{array}{c}\text { Bacteria } \\
\text { (Thermoanaerobacter } \\
\text { brockii) }\end{array}$ & [146] \\
\hline TeBglA & 1 & $80^{\circ} \mathrm{C}$ & 7.0 & $10 \% ; 65^{\circ} \mathrm{C} ; 5 \mathrm{~h}$ & $\begin{array}{c}\text { Bacteria } \\
\text { (Thermoanaerobacter } \\
\text { ethanolicus) }\end{array}$ & [147] \\
\hline TmBglA & 1 & $90{ }^{\circ} \mathrm{C}$ & 6.2 & $>80 \% ; 65^{\circ} \mathrm{C} ; 5 \mathrm{~h}$ & $\begin{array}{c}\text { Bacteria } \\
\text { (Thermotoga maritima) }\end{array}$ & [147] \\
\hline $\mathrm{Bgl}$ & 1 & $70{ }^{\circ} \mathrm{C}$ & 6.4 & $\begin{array}{c}50 \% ; 68^{\circ} \mathrm{C} ; 1 \mathrm{~h} \\
>80 \% ; 60{ }^{\circ} \mathrm{C} ; 2 \mathrm{~h}\end{array}$ & $\begin{array}{c}\text { Bacteria } \\
\text { (Thermoanaerobacterium } \\
\text { thermosaccharolyticum) }\end{array}$ & [148] \\
\hline $\mathrm{BglC}$ & 1 & $50^{\circ} \mathrm{C}$ & 7.0 & $\mathrm{NM}$ & $\begin{array}{c}\text { Bacteria } \\
\text { (Thermobifida fusca) }\end{array}$ & [149] \\
\hline $\mathrm{BglB}$ & 1 & $60^{\circ} \mathrm{C}$ & 6.2 & $70 \% ; 60{ }^{\circ} \mathrm{C} ; 48 \mathrm{~h}$ & $\begin{array}{c}\text { Bacteria } \\
\text { (Thermobispora bispora) }\end{array}$ & [150] \\
\hline BglA & 1 & $80-90{ }^{\circ} \mathrm{C}$ & $7.0-8.0$ & $100 \% ; 70{ }^{\circ} \mathrm{C} ; 6 \mathrm{~h}$ & $\begin{array}{c}\text { Bacteria } \\
\text { (Thermotoga petrophila) }\end{array}$ & {$[151]$} \\
\hline TcaBglA & 1 & $90^{\circ} \mathrm{C}$ & $5.5-6.5$ & $\begin{array}{l}>40 \% ; 80^{\circ} \mathrm{C} ; 30 \mathrm{~min} \\
>20 \% ; 80{ }^{\circ} \mathrm{C} ; 30 \mathrm{~min}\end{array}$ & $\begin{array}{c}\text { Bacteria } \\
\text { (Thermus caldophilus) }\end{array}$ & [152] \\
\hline TnGly & 1 & $90^{\circ} \mathrm{C}$ & 5.6 & $50 \% ; 90{ }^{\circ} \mathrm{C} ; 2.5 \mathrm{~h}$ & $\begin{array}{c}\text { Bacteria } \\
\text { (Thermus nonproteolyticus) }\end{array}$ & [153] \\
\hline
\end{tabular}


Table 5. Cont.

\begin{tabular}{|c|c|c|c|c|c|c|}
\hline Enzyme & $\begin{array}{l}\text { GH family } \\
\text { Domains }\end{array}$ & $\begin{array}{l}\text { Optimum } \\
\text { Temperature }\end{array}$ & $\begin{array}{l}\text { Optimum } \\
\text { pH }\end{array}$ & $\begin{array}{l}\text { Temperature } \\
\text { Stability }\end{array}$ & Source & Reference \\
\hline BglA & 1 & $70{ }^{\circ} \mathrm{C}$ & $5.0-6.0$ & $\begin{array}{c}50 \% ; 70{ }^{\circ} \mathrm{C} ; 38 \mathrm{~h} \\
50 \% ; 80{ }^{\circ} \mathrm{C} ;<0.4 \mathrm{~h} \\
50 \% ; 90{ }^{\circ} \mathrm{C} ;<0.3 \mathrm{~h}\end{array}$ & $\begin{array}{c}\text { Bacteria } \\
\text { (Thermus sp. IB-21) }\end{array}$ & [154] \\
\hline $\mathrm{BglB}$ & 1 & $80^{\circ} \mathrm{C}$ & $5.0-6.0$ & $\begin{array}{c}50 \% ; 70{ }^{\circ} \mathrm{C} ; 38 \mathrm{~h} \\
50 \% ; 80{ }^{\circ} \mathrm{C} ; 2.7 \mathrm{~h} \\
50 \% ; 90{ }^{\circ} \mathrm{C} ; 24 \mathrm{~min}\end{array}$ & $\begin{array}{c}\text { Bacteria } \\
\text { (Thermus sp. IB-21) }\end{array}$ & [154] \\
\hline Bgly & 1 & $90^{\circ} \mathrm{C}$ & 5.4 & $\begin{array}{c}100 \% ; 80{ }^{\circ} \mathrm{C} ; 2 \mathrm{~h} \\
50 \% ; 90{ }^{\circ} \mathrm{C} ; 1.5 \mathrm{~h} \\
50 \% ; 95^{\circ} \mathrm{C} ; 20 \mathrm{~min}\end{array}$ & $\begin{array}{c}\text { Bacteria } \\
\text { (Thermus thermophilus) }\end{array}$ & [155] \\
\hline BglA & 1 & $55^{\circ} \mathrm{C}$ & 6.5 & $\begin{array}{l}82 \% ; 50^{\circ} \mathrm{C} ; 60 \mathrm{~min} \\
20 \% ; 55^{\circ} \mathrm{C} ; 60 \mathrm{~min}\end{array}$ & $\begin{array}{l}\text { Uncultured organism } \\
\text { (soil metagenome) }\end{array}$ & [52] \\
\hline AS-Esc10 & 1 & $60{ }^{\circ} \mathrm{C}$ & 8.0 & $100 \% ; 50{ }^{\circ} \mathrm{C} ; 1 \mathrm{~h}$ & $\begin{array}{l}\text { Uncultured organism } \\
\text { (agricultural soil } \\
\text { metagenome) }\end{array}$ & [40] \\
\hline Bgl-gs1 & 1 & $90^{\circ} \mathrm{C}$ & 6.0 & $\begin{array}{l}50 \% ; 90^{\circ} \mathrm{C} ; 5 \mathrm{~min} \\
50 \% ; 85^{\circ} \mathrm{C} ; 15 \mathrm{~min} \\
50 \% ; 80^{\circ} \mathrm{C} ; 45 \mathrm{~min}\end{array}$ & $\begin{array}{l}\text { Uncultured organism } \\
\text { (termite gut metagenome) }\end{array}$ & [71] \\
\hline $\mathrm{Bgl}$ & 1 & $60^{\circ} \mathrm{C}$ & 5.0 & $50 \% ; 60{ }^{\circ} \mathrm{C} ; 540 \mathrm{~min}$ & $\begin{array}{c}\text { Fungi } \\
\text { (Fusarium oxysporum) }\end{array}$ & [156] \\
\hline Bgl4 & 1 & $55^{\circ} \mathrm{C}$ & 6.0 & $80 \% ; 50{ }^{\circ} \mathrm{C} ; 10 \mathrm{~min}$ & $\begin{array}{c}\text { Fungi } \\
\text { (Humicola grisea var. } \\
\text { thermoidea IFO9854) }\end{array}$ & [157] \\
\hline Bgl1 & 1 & $55^{\circ} \mathrm{C}$ & $5.5-7.5$ & $\begin{array}{l}100 \% ; 50^{\circ} \mathrm{C} ; 8 \mathrm{~h} \\
50 \% ; 55^{\circ} \mathrm{C} ; 8 \mathrm{~h}\end{array}$ & $\begin{array}{c}\text { Fungi } \\
\text { (Orpinomyces sp. PC-2) }\end{array}$ & [158] \\
\hline Bgl1G5 & 1 & $50{ }^{\circ} \mathrm{C}$ & 6.0 & $50 \% ; 50{ }^{\circ} \mathrm{C} ; 6 \mathrm{~h}$ & $\begin{array}{c}\text { Fungi } \\
\text { (Phialophora sp. G5) }\end{array}$ & [159] \\
\hline TaGH2 & 2 & $95^{\circ} \mathrm{C}$ & 6.5 & $\begin{array}{l}100 \% ; 90{ }^{\circ} \mathrm{C} ; 3 \mathrm{~h} \\
50 \% ; 70{ }^{\circ} \mathrm{C} ; 22 \mathrm{~h}\end{array}$ & $\begin{array}{c}\text { Bacteria } \\
\text { (Thermus antranikianii) }\end{array}$ & [160] \\
\hline TbGH2 & 2 & $90{ }^{\circ} \mathrm{C}$ & 6.5 & $\begin{array}{c}17 \% ; 80{ }^{\circ} \mathrm{C} ; 3 \mathrm{~h} \\
50 \% ; 70{ }^{\circ} \mathrm{C} ; 12 \mathrm{~h}\end{array}$ & $\begin{array}{c}\text { Bacteria } \\
\text { (Thermus brockianus) }\end{array}$ & [160] \\
\hline TbBgl & 3 & $90^{\circ} \mathrm{C}$ & 3.5 & $50 \% ; 95^{\circ} \mathrm{C} ; 60 \mathrm{~min}$ & $\begin{array}{c}\text { Arquea } \\
\text { (Thermofilum pendens) }\end{array}$ & [161] \\
\hline BlBG3 & 3 & $50{ }^{\circ} \mathrm{C}$ & 6.0 & NM & $\begin{array}{c}\text { Bacteria } \\
\text { (Bifidobacterium longum) }\end{array}$ & [162] \\
\hline $\mathrm{Cba} 2$ & 3 & $70{ }^{\circ} \mathrm{C}$ & 4.8 & NM & $\begin{array}{c}\text { Bacteria } \\
\text { (Cellulomonas biazotea) }\end{array}$ & [163] \\
\hline CfBgl3A & 3 & $55^{\circ} \mathrm{C}$ & 7.5 & $\mathrm{NM}$ & $\begin{array}{c}\text { Bacteria } \\
\text { (Cellulomonas fimi) }\end{array}$ & [164] \\
\hline Bgl3Z & 3 & $65^{\circ} \mathrm{C}$ & 5.5 & $50 \% ; 60{ }^{\circ} \mathrm{C} ; 5 \mathrm{~h}$ & $\begin{array}{c}\text { Bacteria } \\
\text { (Clostridium stercorarium) }\end{array}$ & [165] \\
\hline Dtur_0219 & 3 & $85^{\circ} \mathrm{C}$ & 5.0 & $\begin{array}{c}50 \% ; 70{ }^{\circ} \mathrm{C} ; 1575 \\
\min \\
50 \% ; 75^{\circ} \mathrm{C} ; 854 \mathrm{~min} \\
50 \% ; 80{ }^{\circ} \mathrm{C} ; 524 \mathrm{~min} \\
50 \% ; 85^{\circ} \mathrm{C} ; 334 \mathrm{~min} \\
50 \% ; 90^{\circ} \mathrm{C} ; 20 \mathrm{~min}\end{array}$ & $\begin{array}{c}\text { Bacteria (Dictyoglomus } \\
\text { turgidum) }\end{array}$ & [54] \\
\hline $\mathrm{Bgl}$ & 3 & $50{ }^{\circ} \mathrm{C}$ & $4.2-5.0$ & NM & $\begin{array}{c}\text { Bacteria } \\
\text { (Elizabethkingia } \\
\text { meningoseptica) }\end{array}$ & [166] \\
\hline TmBglB & 3 & $80^{\circ} \mathrm{C}$ & 4.2 & $>80 \% ; 65^{\circ} \mathrm{C} ; 5 \mathrm{~h}$ & $\begin{array}{c}\text { Bacteria } \\
\text { (Thermotoga maritima) }\end{array}$ & [147] \\
\hline Tpebgl3 & 3 & $90^{\circ} \mathrm{C}$ & 5.0 & $\begin{array}{l}>90 \% ; 70{ }^{\circ} \mathrm{C} ; 3 \mathrm{~h} \\
>50 \% ; 90^{\circ} \mathrm{C} ; 3 \mathrm{~h}\end{array}$ & $\begin{array}{c}\text { Bacteria } \\
\text { (Thermotoga petrophila) }\end{array}$ & [167] \\
\hline Cel3A & 3 & $50-60^{\circ} \mathrm{C}$ & 5.0 & $\begin{aligned} & 98 \% ; 60{ }^{\circ} \mathrm{C} ; 6 \mathrm{~h} \\
> & 50 \% ; 60{ }^{\circ} \mathrm{C} ; 24 \mathrm{~h} \\
> & 50 \% ; 70{ }^{\circ} \mathrm{C} ; 24 \mathrm{~h}\end{aligned}$ & $\begin{array}{c}\text { Fungi } \\
\text { (Amesia atrobrunnea) }\end{array}$ & [168] \\
\hline Cel3B & 3 & $50-60{ }^{\circ} \mathrm{C}$ & 5.0 & $\begin{aligned} & 88 \% ; 60{ }^{\circ} \mathrm{C} ; 6 \mathrm{~h} \\
> & 50 \% ; 60{ }^{\circ} \mathrm{C} ; 24 \mathrm{~h} \\
> & 50 \% ; 70{ }^{\circ} \mathrm{C} ; 24 \mathrm{~h}\end{aligned}$ & $\begin{array}{c}\text { Fungi } \\
\text { (Amesia atrobrunnea) }\end{array}$ & [168] \\
\hline $\mathrm{Bgl3}$ & 3 & $60{ }^{\circ} \mathrm{C}$ & 6.0 & $>50 \% ; 70{ }^{\circ} \mathrm{C} ; 1 \mathrm{~h}$ & $\begin{array}{c}\text { Fungi } \\
\text { (Aspergillus fumigatus) }\end{array}$ & [169] \\
\hline $\mathrm{BglB}$ & 3 & $52{ }^{\circ} \mathrm{C}$ & 5.5 & $\mathrm{NM}$ & $\begin{array}{c}\text { Fungi } \\
\text { (Aspergillus nidulans) }\end{array}$ & [78] \\
\hline BglC & 3 & $52{ }^{\circ} \mathrm{C}$ & 6.0 & NM & $\begin{array}{c}\text { Fungi } \\
\text { (Aspergillus nidulans) }\end{array}$ & [78] \\
\hline Bgl & 3 & $50^{\circ} \mathrm{C}$ & 5.0 & $\begin{array}{l}100 \% ; 50{ }^{\circ} \mathrm{C} ; 30 \mathrm{~min} \\
60 \% ; 60^{\circ} \mathrm{C} ; 30 \mathrm{~min}\end{array}$ & $\begin{array}{c}\text { Fungi } \\
\text { (Aspergillus oryzae) }\end{array}$ & [49] \\
\hline $\mathrm{Bgl}$ & 3 & $60^{\circ} \mathrm{C}$ & 5.0 & $\begin{array}{c}67.7 \% ; 60{ }^{\circ} \mathrm{C} ; 1 \mathrm{~h} \\
50 \% ; 65{ }^{\circ} \mathrm{C} ; 55 \mathrm{~min} \\
29.7 \% ; 70{ }^{\circ} \mathrm{C} ; 10 \mathrm{~min}\end{array}$ & $\begin{array}{l}\text { Fungi } \\
\text { (Chaetomium } \\
\text { thermophilum) }\end{array}$ & [170] \\
\hline
\end{tabular}


Table 5. Cont.

\begin{tabular}{|c|c|c|c|c|c|c|}
\hline Enzyme & $\begin{array}{l}\text { GH family } \\
\text { Domains }\end{array}$ & $\begin{array}{l}\text { Optimum } \\
\text { Temperature }\end{array}$ & $\begin{array}{c}\text { Optimum } \\
\mathrm{pH}\end{array}$ & $\begin{array}{l}\text { Temperature } \\
\text { Stability }^{1}\end{array}$ & Source & Reference \\
\hline Bx15 & 3 & $75^{\circ} \mathrm{C}$ & 4.6 & $\begin{array}{c}50 \% ; 65^{\circ} \mathrm{C} ; 5 \mathrm{~h} \\
50 \% ; 70{ }^{\circ} \mathrm{C} ; 20 \mathrm{~min} \\
50 \% ; 75^{\circ} \mathrm{C} ; 5 \mathrm{~min}\end{array}$ & $\begin{array}{c}\text { Fungi } \\
\text { (Chrysosporium } \\
\text { lucknowense) }\end{array}$ & [171] \\
\hline MoCel3A & 3 & $50^{\circ} \mathrm{C}$ & $5.0-5.5$ & NM & $\begin{array}{c}\text { Fungi } \\
\text { (Magnaporthe oryzae) }\end{array}$ & [41] \\
\hline MoCel3B & 3 & $50^{\circ} \mathrm{C}$ & $5.0-5.5$ & $\mathrm{NM}$ & $\begin{array}{c}\text { Fungi } \\
\text { (Magnaporthe oryzae) }\end{array}$ & [41] \\
\hline Bgl2 & 3 & $60^{\circ} \mathrm{C}$ & 5.4 & $\begin{array}{l}>50 \% ; 40{ }^{\circ} \mathrm{C} ; 2 \mathrm{~h} \\
>45 \% ; 50{ }^{\circ} \mathrm{C} ; 2 \mathrm{~h} \\
25 \% ; 55^{\circ} \mathrm{C} ; 1 \mathrm{~h}\end{array}$ & $\begin{array}{c}\text { Fungi } \\
\text { (Neurospora crassa) }\end{array}$ & [172] \\
\hline Bgl1 & 3 & $50^{\circ} \mathrm{C}$ & $3.5-5.0$ & $100 \% ; 45^{\circ} \mathrm{C} ; 30 \mathrm{~min}$ & $\begin{array}{c}\text { Fungi } \\
\text { (Mucor circinelloides) }\end{array}$ & [173] \\
\hline $\mathrm{Bg} 12$ & 3 & $55^{\circ} \mathrm{C}$ & $3.5-5.5$ & $100 \% ; 55^{\circ} \mathrm{C} ; 30 \mathrm{~min}$ & $\begin{array}{c}\text { Fungi } \\
\text { (Mucor circinelloides) }\end{array}$ & [173] \\
\hline NfBGL1 & 3 & $80^{\circ} \mathrm{C}$ & 5.0 & $>80 \% ; 70{ }^{\circ} \mathrm{C} ; 2 \mathrm{~h}$ & $\begin{array}{c}\text { Fungi } \\
\text { (Neosartorya fischeri) }\end{array}$ & [174] \\
\hline PtBglu3 & 3 & $65^{\circ} \mathrm{C}$ & 6.0 & $>85 \% ; 60{ }^{\circ} \mathrm{C} ; 30 \mathrm{~min}$ & $\begin{array}{c}\text { Fungi } \\
\text { (Paecilomyces thermophila) }\end{array}$ & {$[32]$} \\
\hline Bgl1 & 3 & $70^{\circ} \mathrm{C}$ & 4.8 & $50 \% ; 65^{\circ} \mathrm{C} ; 24 \mathrm{~h}$ & $\begin{array}{c}\text { Fungi } \\
\text { (Penicillium brasilianum) }\end{array}$ & [175] \\
\hline pBGL1 & 3 & $65-70^{\circ} \mathrm{C}$ & $4.5-5.50$ & $\begin{array}{c}96.3 \% ; 50{ }^{\circ} \mathrm{C} ; 12 \mathrm{~h} \\
50 \% ; 70{ }^{\circ} \mathrm{C} ; 4 \mathrm{~h}\end{array}$ & $\begin{array}{c}\text { Fungi } \\
\text { (Penicillium decumbens) }\end{array}$ & [176] \\
\hline Bgl1 & 3 & $70^{\circ} \mathrm{C}$ & $5.0-6.0$ & $60 \% ; 70^{\circ} \mathrm{C} ; 1.5 \mathrm{~h}$ & $\begin{array}{c}\text { Fungi } \\
\text { (Periconia } \mathrm{sp} .)\end{array}$ & [43] \\
\hline RmBglu3B & 3 & $50^{\circ} \mathrm{C}$ & 5.0 & $50 \% ; 50{ }^{\circ} \mathrm{C} ; 30 \mathrm{~min}$ & $\begin{array}{c}\text { Fungi } \\
\text { (Rhizomucor miehei) }\end{array}$ & {$[50]$} \\
\hline Bgl1 & 3 & $50{ }^{\circ} \mathrm{C}$ & 5.0 & $\begin{array}{l}>70 \% ; 50{ }^{\circ} \mathrm{C} ; 30 \mathrm{~min} \\
<10 \% ; 60{ }^{\circ} \mathrm{C} ; 30 \mathrm{~min}\end{array}$ & $\begin{array}{c}\text { Fungi } \\
\text { (Saccharomycopsis } \\
\text { fibuligera) }\end{array}$ & [177] \\
\hline $\mathrm{Bg} 12$ & 3 & $50{ }^{\circ} \mathrm{C}$ & 5.0 & $\begin{array}{l}>70 \% ; 50{ }^{\circ} \mathrm{C} ; 30 \mathrm{~min} \\
<10 \% ; 60{ }^{\circ} \mathrm{C} ; 30 \mathrm{~min}\end{array}$ & $\begin{array}{c}\text { Fungi } \\
\text { (Saccharomycopsis } \\
\text { fibuligera) }\end{array}$ & [177] \\
\hline$\beta$-glucosidase & 3 & $75^{\circ} \mathrm{C}$ & 4.5 & $\begin{array}{c}50 \% ; 60^{\circ} \mathrm{C} ; 136 \mathrm{~h} \\
50 \% ; 65^{\circ} \mathrm{C} ; 55 \mathrm{~h} \\
50 \% ; 70^{\circ} \mathrm{C} ; 10 \mathrm{~h} \\
50 \% ; 75^{\circ} \mathrm{C} ; 1 \mathrm{~h}\end{array}$ & $\begin{array}{c}\text { Fungi } \\
\text { (Talaromyces aculeatus) }\end{array}$ & [53] \\
\hline Cel3a & 3 & $71.5^{\circ} \mathrm{C}$ & 4.02 & $\begin{array}{l}50 \% ; 65^{\circ} \mathrm{C} ; 62 \mathrm{~min} \\
50 \% ; 75^{\circ} \mathrm{C} ; 18 \mathrm{~min}\end{array}$ & $\begin{array}{c}\text { Fungi } \\
\text { (Talaromyces emersonii) }\end{array}$ & [178] \\
\hline $\mathrm{Bgl} 3 \mathrm{~A}$ & 3 & $75^{\circ} \mathrm{C}$ & 4.5 & $>65 \% ; 60{ }^{\circ} \mathrm{C} ; 1 \mathrm{~h}$ & $\begin{array}{c}\text { Fungi } \\
\text { (Talaromyces leycettanus) }\end{array}$ & [179] \\
\hline Bgl1 & 3 & $70^{\circ} \mathrm{C}$ & 5.0 & $>70 \% ; 60{ }^{\circ} \mathrm{C} ; 1 \mathrm{~h}$ & $\begin{array}{c}\text { Fungi } \\
\text { (Thermoascus auranticus) }\end{array}$ & [180] \\
\hline $\mathrm{Bgl} 3 \mathrm{a}$ & 3 & $70{ }^{\circ} \mathrm{C}$ & 5.0 & $50 \% ; 60{ }^{\circ} \mathrm{C} ; 143 \mathrm{~min}$ & $\begin{array}{c}\text { Fungi } \\
\text { (Myceliophthora } \\
\text { thermophila) }\end{array}$ & [181] \\
\hline RG3 & 3 & $50-55^{\circ} \mathrm{C}$ & $5.5-6.0$ & NM & $\begin{array}{l}\text { Uncultured organism } \\
\text { (Rabbit cecum } \\
\text { metagenome) }\end{array}$ & [67] \\
\hline RG14 & 3 & $50-55^{\circ} \mathrm{C}$ & $5.5-7.0$ & $\mathrm{NM}$ & $\begin{array}{l}\text { Uncultured organism } \\
\text { (Rabbit cecum } \\
\text { metagenome) }\end{array}$ & [67] \\
\hline BGL7 & 3 & $50{ }^{\circ} \mathrm{C}$ & 6.5 & NM & $\begin{array}{l}\text { Uncultured organism } \\
\text { (Termite gut } \\
\text { metagenome) }\end{array}$ & {$[72]$} \\
\hline LAB25g2 & 3 & $55^{\circ} \mathrm{C}$ & 4.5 & $82 \% ; 50{ }^{\circ} \mathrm{C} ; 5 \mathrm{~d}$ & $\begin{array}{l}\text { Uncultured organism } \\
\text { (Cow rumen } \\
\text { metagenome) }\end{array}$ & {$[68]$} \\
\hline SRF2g14 & 3 & $55^{\circ} \mathrm{C}$ & 5.0 & $50 \% ; 50{ }^{\circ} \mathrm{C} ; 18.06 \mathrm{~h}$ & $\begin{array}{l}\text { Uncultured organism } \\
\text { (Cow rumen } \\
\text { metagenome) }\end{array}$ & [68] \\
\hline SRF2g18 & 3 & $50{ }^{\circ} \mathrm{C}$ & 4.0 & $50 \% ; 50{ }^{\circ} \mathrm{C} ; 37.5 \mathrm{~h}$ & $\begin{array}{c}\text { Uncultured organism } \\
\text { (Cow rumen } \\
\text { metagenome) }\end{array}$ & [68] \\
\hline RuBGX1 & 3 & $50{ }^{\circ} \mathrm{C}$ & 6.0 & $62 \% ; 50{ }^{\circ} \mathrm{C} ; 10 \mathrm{~min}$ & $\begin{array}{c}\text { Uncultured organism } \\
\text { (Yak rumen metagenome) }\end{array}$ & [36] \\
\hline JMB19063 & 3 & $50-55^{\circ} \mathrm{C}$ & 6.5 & $\mathrm{NM}$ & $\begin{array}{l}\text { Uncultured organism } \\
\text { (Compost metagenome) }\end{array}$ & [37] \\
\hline GlyA1 & 3 & $55^{\circ} \mathrm{C}$ & 6.5 & $\mathrm{NM}$ & $\begin{array}{l}\text { Uncultured organism } \\
\text { (Cow rumen } \\
\text { metagenome) }\end{array}$ & [69] \\
\hline
\end{tabular}


Table 5. Cont.

\begin{tabular}{|c|c|c|c|c|c|c|}
\hline Enzyme & $\begin{array}{l}\text { GH family } \\
\text { Domains }\end{array}$ & $\begin{array}{c}\text { Optimum } \\
\text { Temperature }\end{array}$ & $\begin{array}{l}\text { Optimum } \\
\text { pH }\end{array}$ & $\begin{array}{l}\text { Temperature } \\
\text { Stability }\end{array}$ & Source & Reference \\
\hline Bgx1 & 30 & $50{ }^{\circ} \mathrm{C}$ & $4.0-6.0$ & NM & $\begin{array}{c}\text { Oomycota } \\
\text { (Phytophthora infestans) }\end{array}$ & [182] \\
\hline SSO3039 & 116 & $>70^{\circ} \mathrm{C}$ & 4.0 & $\begin{array}{l}>70 \% ; 65^{\circ} \mathrm{C} ; 48 \mathrm{~h} \\
>50 \% ; 85^{\circ} \mathrm{C} ; 8 \mathrm{~h}\end{array}$ & $\begin{array}{c}\text { Arquea } \\
\text { (Sulfolobus solfataricus) }\end{array}$ & [183] \\
\hline TxGH116 & 116 & $85^{\circ} \mathrm{C}$ & 6.0 & $\mathrm{NM}$ & $\begin{array}{c}\text { Bacteria } \\
\text { (Thermoanaerobacterium } \\
\text { xylanolyticum) }\end{array}$ & [184] \\
\hline
\end{tabular}

${ }^{1}$ Temperature stability is given as a percentage of activity (residual activity) after treatment at the specified temperature and time compared to the untreated enzyme.

\section{Conclusions}

Cellulases retrieved from high-temperature environments are considered a valuable industrial resource for their vast biotechnological potential [35]. The use of culture-independent techniques such as metagenomics has allowed us to discover enzymes from unknown microorganisms thriving in extreme habitats [11]. Since the last decade, metagenomics has led to the discovery of almost half $(46 \%)$ of the characterized thermophilic endoglucanases (Table 1) described in that period and a fraction (17\% of each total) of the thermophilic cellobiosidases acting on the non-reducing end of cellulose (Table 2) and thermophilic $\beta$-glucosidases (Table 5). Nevertheless, metagenomics have yet to yield thermophilic cellobiosidases acting on the reducing end of cellulose (Table 3) or thermophilic cellodextrinases (Table 4). The lack of enzymes found by this strategy is likely a consequence of the mechanism of action of those enzymes, as the lack of substrates specific to those activities greatly limits its positive hit ratio. While thermophilic $\beta$-glucosidases discovered in the last 5 years still account for a similar proportion of the total $(15 \%)$, no more thermophilic cellobiosidases acting on non-reducing ends have been characterized by this method. On the other hand, the proportion of thermophilic endoglucanases that have been characterized and identified by metagenomics have grown to account for more than half of the total $(55 \%)$ in the last 5 years. In total, almost one fifth $(18 \%)$ of all the thermophilic cellulases identified and characterized so far have been found by metagenomics. Functional metagenomic bottlenecks, like the lack of substrates for specific cellulases and problems associated with heterologous expression [3], and validation of sequence-based metagenomics annotation of cellulases [11], still need to be addressed to further increase the number of cellulases identified using these strategies. Biomining for novel thermophilic cellulases through metagenomic means is thus an ongoing challenge, with great potential as a source of commercially and environmentally important byocatalysts in all sorts of biotechnological applications.

Author Contributions: Writing-original draft preparation: J.-J.E.-R.; writing—review \& editing, J.-J.E.-R., M.-E.D., M.-E.C., E.R.-B., M.B., M.-I.G.-S.; project administration: M.-I.G.-S.; funding acquisition: M.-E.C., M.-I.G.-S.

Funding: General support for EXPRELA (Universidade da Coruna, Spain) was funded by the Xunta de Galicia (Consolidación Grupos Referencia Competitiva Contract no. ED431C2016-012), co-financed by FEDER (EEC).

Acknowledgments: HOTDROPS (FP7/2007-2013, CN 324439).

Conflicts of Interest: The authors declare no conflict of interest. The funders had no role in the design of the study; in the collection, analyses, or interpretation of data; in the writing of the manuscript; or in the decision to publish the results.

\section{References}

1. Sandgren, M.; Ståhlberg, J.; Mitchinson, C. Structural and biochemical studies of GH family 12 cellulases: Improved thermal stability, and ligand complexes. Prog. Biophys. Mol. Biol. 2005, 89, 246-291. [CrossRef] [PubMed] 
2. Blumer-Schuette, S.E.; Kataeva, I.; Westpheling, J.; Adams, M.W.; Kelly, R.M. Extremely thermophilic microorganisms for biomass conversion: Status and prospects. Curr. Opin. Biotechnol. 2008, 19, 210-217. [CrossRef] [PubMed]

3. Duan, C.-J.; Feng, J.-X. Mining metagenomes for novel cellulase genes. Biotechnol. Lett. 2010, 32, $1765-1775$. [CrossRef] [PubMed]

4. Sharma, A.; Tewari, R.; Rana, S.S.; Soni, R.; Soni, S.K. Cellulases: Classification, Methods of Determination and Industrial Applications. Appl. Biochem. Biotechnol. 2016, 179, 1346-1380. [CrossRef] [PubMed]

5. Couturier, M.; Feliu, J.; Haon, M.; Navarro, D.; Lesage-Meessen, L.; Coutinho, P.M.; Berrin, J.-G. A thermostable GH45 endoglucanase from yeast: Impact of its atypical multimodularity on activity. Microb. Cell Fact. 2011, 10, 103. [CrossRef] [PubMed]

6. López-Mondéjar, R.; Zühlke, D.; Becher, D.; Riedel, K.; Baldrian, P. Cellulose and hemicellulose decomposition by forest soil bacteria proceeds by the action of structurally variable enzymatic systems. Sci. Rep. 2016, 6, 25279. [CrossRef] [PubMed]

7. Kaur, B.; Chadha, B.S. Approaches for Bioprospecting Cellulases. In Extremophilic Enzymatic Processing of Lignocellulosic Feedstocks to Bioenergy; Sani, R.K., Krishnaraj, R.N., Eds.; Springer International Publishing: Cham, Switzerland, 2017; pp. 53-71, ISBN 978-3-319-54683-4.

8. Bok, J.D.; Yernool, D.A.; Eveleigh, D.E. Purification, characterization, and molecular analysis of thermostable cellulases CelA and CelB from Thermotoga neapolitana. Appl. Environ. Microbiol. 1998, 64, 4774-4781. [PubMed]

9. Elleuche, S.; Schäfers, C.; Blank, S.; Schröder, C.; Antranikian, G. Exploration of extremophiles for high temperature biotechnological processes. Curr. Opin. Microbiol. 2015, 25, 113-119. [CrossRef] [PubMed]

10. Tiwari, R.; Nain, L.; Labrou, N.E.; Shukla, P. Bioprospecting of functional cellulases from metagenome for second generation biofuel production: A review. Crit. Rev. Microbiol. 2018, 44, 244-257. [CrossRef] [PubMed]

11. DeCastro, M.-E.; Rodríguez-Belmonte, E.; González-Siso, M.-I. Metagenomics of Thermophiles with a Focus on Discovery of Novel Thermozymes. Front. Microbiol. 2016, 7, 1521. [CrossRef] [PubMed]

12. Wagner, I.D.; Wiegel, J. Diversity of thermophilic anaerobes. Ann. N. Y. Acad. Sci. 2008, 1125, 1-43. [CrossRef] [PubMed]

13. Liu, Y.; Zhang, J.; Liu, Q.; Zhang, C.; Ma, Q. Molecular cloning of novel cellulase genes cel9A and cel12A from Bacillus licheniformis GXN151 and synergism of their encoded polypeptides. Curr. Microbiol. 2004, 49, 234-238. [CrossRef] [PubMed]

14. Crennell, S.J.; Hreggvidsson, G.O.; Nordberg Karlsson, E. The structure of Rhodothermus marinus Cel12A, a highly thermostable family 12 endoglucanase, at 1.8 A resolution. J. Mol. Biol. 2002, 320, 883-897. [CrossRef]

15. Chhabra, S.R.; Kelly, R.M. Biochemical characterization of Thermotoga maritima endoglucanase Cel74 with and without a carbohydrate binding module (CBM). FEBS Lett. 2002, 531, 375-380. [CrossRef]

16. Peer, A.; Smith, S.P.; Bayer, E.A.; Lamed, R.; Borovok, I. Noncellulosomal cohesin- and dockerin-like modules in the three domains of life. FEMS Microbiol. Lett. 2009, 291, 1-16. [CrossRef] [PubMed]

17. Bayer, E.A.; Belaich, J.-P.; Shoham, Y.; Lamed, R. The cellulosomes: Multienzyme machines for degradation of plant cell wall polysaccharides. Annu. Rev. Microbiol. 2004, 58, 521-554. [CrossRef] [PubMed]

18. Sathya, T.A.; Khan, M. Diversity of glycosyl hydrolase enzymes from metagenome and their application in food industry. J. Food Sci. 2014, 79, R2149-R2156. [CrossRef] [PubMed]

19. Poidevin, L.; Feliu, J.; Doan, A.; Berrin, J.-G.; Bey, M.; Coutinho, P.M.; Henrissat, B.; Record, E.; Heiss-Blanquet, S. Insights into exo- and endoglucanase activities of family 6 glycoside hydrolases from Podospora anserina. Appl. Environ. Microbiol. 2013, 79, 4220-4229. [CrossRef] [PubMed]

20. Henrissat, B. A classification of glycosyl hydrolases based on amino acid sequence similarities. Biochem. J. 1991, 280, 309-316. [CrossRef] [PubMed]

21. Lombard, V.; Golaconda Ramulu, H.; Drula, E.; Coutinho, P.M.; Henrissat, B. The carbohydrate-active enzymes database (CAZy) in 2013. Nucleic Acids Res. 2014, 42, D490-D495. [CrossRef] [PubMed]

22. Kim, D.Y.; Lee, M.J.; Cho, H.-Y.; Lee, J.S.; Lee, M.-H.; Chung, C.W.; Shin, D.-H.; Rhee, Y.H.; Son, K.-H.; Park, H.-Y. Genetic and functional characterization of an extracellular modular GH6 endo- $\beta$-1,4-glucanase from an earthworm symbiont, Cellulosimicrobium funkei HY-13. Antonie Van Leeuwenhoek 2016, 109, 1-12. [CrossRef] [PubMed] 
23. Halldórsdóttir, S.; Thórólfsdóttir, E.T.; Spilliaert, R.; Johansson, M.; Thorbjarnardóttir, S.H.; Palsdottir, A.; Hreggvidsson, G.O.; Kristjánsson, J.K.; Holst, O.; Eggertsson, G. Cloning, sequencing and overexpression of a Rhodothermus marinus gene encoding a thermostable cellulase of glycosyl hydrolase family 12 . Appl. Microbiol. Biotechnol. 1998, 49, 277-284. [CrossRef] [PubMed]

24. Ausili, A.; Cobucci-Ponzano, B.; Di Lauro, B.; D'Avino, R.; Perugino, G.; Bertoli, E.; Scirè, A.; Rossi, M.; Tanfani, F.; Moracci, M. A comparative infrared spectroscopic study of glycoside hydrolases from extremophilic archaea revealed different molecular mechanisms of adaptation to high temperatures. Proteins 2007, 67, 991-1001. [CrossRef] [PubMed]

25. Aguilar, C.F.; Sanderson, I.; Moracci, M.; Ciaramella, M.; Nucci, R.; Rossi, M.; Pearl, L.H. Crystal structure of the $\beta$-glycosidase from the hyperthermophilic archeon Sulfolobus solfataricus: Resilience as a key factor in thermostability. J. Mol. Biol. 1997, 271, 789-802. [CrossRef] [PubMed]

26. Wu, I.; Arnold, F.H. Engineered thermostable fungal Cel6A and Cel7A cellobiohydrolases hydrolyze cellulose efficiently at elevated temperatures. Biotechnol. Bioeng. 2013, 110, 1874-1883. [CrossRef] [PubMed]

27. Rawat, R.; Kumar, S.; Chadha, B.S.; Kumar, D.; Oberoi, H.S. An acidothermophilic functionally active novel GH12 family endoglucanase from Aspergillus niger HO: Purification, characterization and molecular interaction studies. Antonie Van Leeuwenhoek 2015, 107, 103-117. [CrossRef] [PubMed]

28. Voutilainen, S.P.; Puranen, T.; Siika-Aho, M.; Lappalainen, A.; Alapuranen, M.; Kallio, J.; Hooman, S.; Viikari, L.; Vehmaanperä, J.; Koivula, A. Cloning, expression, and characterization of novel thermostable family 7 cellobiohydrolases. Biotechnol. Bioeng. 2008, 101, 515-528. [CrossRef] [PubMed]

29. Voutilainen, S.P.; Murray, P.G.; Tuohy, M.G.; Koivula, A. Expression of Talaromyces emersonii cellobiohydrolase Cel7A in Saccharomyces cerevisiae and rational mutagenesis to improve its thermostability and activity. Protein Eng. Des. Sel. 2010, 23, 69-79. [CrossRef] [PubMed]

30. Li, Y.-L.; Li, H.; Li, A.-N.; Li, D.-C. Cloning of a gene encoding thermostable cellobiohydrolase from the thermophilic fungus Chaetomium thermophilum and its expression in Pichia pastoris. J. Appl. Microbiol. 2009, 106, 1867-1875. [CrossRef] [PubMed]

31. Karnaouri, A.C.; Topakas, E.; Christakopoulos, P. Cloning, expression, and characterization of a thermostable GH7 endoglucanase from Myceliophthora thermophila capable of high-consistency enzymatic liquefaction. Appl. Microbiol. Biotechnol. 2014, 98, 231-242. [CrossRef] [PubMed]

32. Yan, Q.; Hua, C.; Yang, S.; Li, Y.; Jiang, Z. High level expression of extracellular secretion of a $\beta$-glucosidase gene (PtBglu3) from Paecilomyces thermophila in Pichia pastoris. Protein Expr. Purif. 2012, 84, 64-72. [CrossRef] [PubMed]

33. Liu, Y.; Dun, B.; Shi, P.; Ma, R.; Luo, H.; Bai, Y.; Xie, X.; Yao, B. A Novel GH7 Endo- $\beta-1,4-G l u c a n a s e$ from Neosartorya fischeri $\mathrm{P} 1$ with Good Thermostability, Broad Substrate Specificity and Potential Application in the Brewing Industry. PLoS ONE 2015, 10, e0137485. [CrossRef] [PubMed]

34. Dougherty, M.J.; D’haeseleer, P.; Hazen, T.C.; Simmons, B.A.; Adams, P.D.; Hadi, M.Z. Glycoside hydrolases from a targeted compost metagenome, activity-screening and functional characterization. BMC Biotechnol. 2012, 12, 38. [CrossRef] [PubMed]

35. Wang, J.; Gao, G.; Li, Y.; Yang, L.; Liang, Y.; Jin, H.; Han, W.; Feng, Y.; Zhang, Z. Cloning, Expression, and Characterization of a Thermophilic Endoglucanase, AcCel12B from Acidothermus cellulolyticus 11B. Int. J. Mol. Sci. 2015, 16, 25080-25095. [CrossRef] [PubMed]

36. Zhou, J.; Bao, L.; Chang, L.; Liu, Z.; You, C.; Lu, H. Beta-xylosidase activity of a GH3 glucosidase/xylosidase from yak rumen metagenome promotes the enzymatic degradation of hemicellulosic xylans. Lett. Appl. Microbiol. 2012, 54, 79-87. [CrossRef] [PubMed]

37. McAndrew, R.P.; Park, J.I.; Heins, R.A.; Reindl, W.; Friedland, G.D.; D’haeseleer, P.; Northen, T.; Sale, K.L.; Simmons, B.A.; Adams, P.D. From soil to structure, a novel dimeric $\beta$-glucosidase belonging to glycoside hydrolase family 3 isolated from compost using metagenomic analysis. J. Biol. Chem. 2013, 288, 14985-14992. [CrossRef] [PubMed]

38. Lee, C.-M.; Lee, Y.-S.; Seo, S.-H.; Yoon, S.-H.; Kim, S.-J.; Hahn, B.-S.; Sim, J.-S.; Koo, B.-S. Screening and Characterization of a Novel Cellulase Gene from the Gut Microflora of Hermetia illucens Using Metagenomic Library. J. Microbiol. Biotechnol. 2014, 24, 1196-1206. [CrossRef] [PubMed]

39. Girfoglio, M.; Rossi, M.; Cannio, R. Cellulose degradation by Sulfolobus solfataricus requires a cell-anchored endo- $\beta$-1-4-glucanase. J. Bacteriol. 2012, 194, 5091-5100. [CrossRef] [PubMed] 
40. Biver, S.; Stroobants, A.; Portetelle, D.; Vandenbol, M. Two promising alkaline $\beta$-glucosidases isolated by functional metagenomics from agricultural soil, including one showing high tolerance towards harsh detergents, oxidants and glucose. J. Ind. Microbiol. Biotechnol. 2014, 41, 479-488. [CrossRef] [PubMed]

41. Takahashi, M.; Konishi, T.; Takeda, T. Biochemical characterization of Magnaporthe oryzae $\beta$-glucosidases for efficient $\beta$-glucan hydrolysis. Appl. Microbiol. Biotechnol. 2011, 91, 1073-1082. [CrossRef] [PubMed]

42. Bhalla, A.; Bansal, N.; Kumar, S.; Bischoff, K.M.; Sani, R.K. Improved lignocellulose conversion to biofuels with thermophilic bacteria and thermostable enzymes. Bioresour. Technol. 2013, 128, 751-759. [CrossRef] [PubMed]

43. Harnpicharnchai, P.; Champreda, V.; Sornlake, W.; Eurwilaichitr, L. A thermotolerant beta-glucosidase isolated from an endophytic fungi, Periconia sp., with a possible use for biomass conversion to sugars. Protein Expr. Purif. 2009, 67, 61-69. [CrossRef] [PubMed]

44. Fusco, F.A.; Fiorentino, G.; Pedone, E.; Contursi, P.; Bartolucci, S.; Limauro, D. Biochemical characterization of a novel thermostable $\beta$-glucosidase from Dictyoglomus turgidum. Int. J. Biol. Macromol. 2018, 113, 783-791. [CrossRef] [PubMed]

45. Boyce, A.; Walsh, G. Characterisation of a novel thermostable endoglucanase from Alicyclobacillus vulcanalis of potential application in bioethanol production. Appl. Microbiol. Biotechnol. 2015, 99, 7515-7525. [CrossRef] [PubMed]

46. Ando, S.; Ishida, H.; Kosugi, Y.; Ishikawa, K. Hyperthermostable Endoglucanase from Pyrococcus horikoshii. Appl. Environ. Microbiol. 2002, 68, 430-433. [CrossRef] [PubMed]

47. Bai, Y.; Wang, J.; Zhang, Z.; Shi, P.; Luo, H.; Huang, H.; Feng, Y.; Yao, B. Extremely acidic beta-1,4-glucanase, CelA4, from thermoacidophilic Alicyclobacillus sp. A4 with high protease resistance and potential as a pig feed additive. J. Agric. Food Chem. 2010, 58, 1970-1975. [CrossRef] [PubMed]

48. Vuong, T.V.; Wilson, D.B. Processivity, synergism, and substrate specificity of Thermobifida fusca Cel6B. Appl. Environ. Microbiol. 2009, 75, 6655-6661. [CrossRef] [PubMed]

49. Tang, Z.; Liu, S.; Jing, H.; Sun, R.; Liu, M.; Chen, H.; Wu, Q.; Han, X. Cloning and expression of A. oryzae $\beta$-glucosidase in Pichia pastoris. Mol. Biol. Rep. 2014, 41, 7567-7573. [CrossRef] [PubMed]

50. Guo, Y.; Yan, Q.; Yang, Y.; Yang, S.; Liu, Y.; Jiang, Z. Expression and characterization of a novel $\beta$-glucosidase, with transglycosylation and exo- $\beta$-1,3-glucanase activities, from Rhizomucor miehei. Food Chem. 2015, 175, 431-438. [CrossRef] [PubMed]

51. Villanueva, A.; Ramón, D.; Vallés, S.; Lluch, M.A.; MacCabe, A.P. Heterologous Expression in Aspergillus nidulans of a Trichoderma longibrachiatum Endoglucanase of Enological Relevance. J. Agric. Food Chem. 2000, 48, 951-957. [CrossRef] [PubMed]

52. Kim, S.-J.; Lee, C.-M.; Kim, M.-Y.; Yeo, Y.-S.; Yoon, S.-H.; Kang, H.-C.; Koo, B.-S. Screening and characterization of an enzyme with beta-glucosidase activity from environmental DNA. J. Microbiol. Biotechnol. 2007, 17, 905-912. [PubMed]

53. Lee, G.-W.; Yoo, M.-H.; Shin, K.-C.; Kim, K.-R.; Kim, Y.-S.; Lee, K.-W.; Oh, D.-K. $\beta$-glucosidase from Penicillium aculeatum hydrolyzes exo-, 3-O-, and 6-O- $\beta$-glucosides but not 20-O- $\beta$-glucoside and other glycosides of ginsenosides. Appl. Microbiol. Biotechnol. 2013, 97, 6315-6324. [CrossRef] [PubMed]

54. Kim, Y.-S.; Yeom, S.-J.; Oh, D.-K. Characterization of a GH3 family $\beta$-glucosidase from Dictyoglomus turgidum and its application to the hydrolysis of isoflavone glycosides in spent coffee grounds. J. Agric. Food Chem. 2011, 59, 11812-11818. [CrossRef] [PubMed]

55. Kumar, P.; Ryan, B.; Henehan, G.T.M. $\beta$-Glucosidase from Streptomyces griseus: Nanoparticle immobilisation and application to alkyl glucoside synthesis. Protein Expr. Purif. 2017, 132, 164-170. [CrossRef] [PubMed]

56. Placido, A.; Hai, T.; Ferrer, M.; Chernikova, T.N.; Distaso, M.; Armstrong, D.; Yakunin, A.F.; Toshchakov, S.V.; Yakimov, M.M.; Kublanov, I.V.; et al. Diversity of hydrolases from hydrothermal vent sediments of the Levante Bay, Vulcano Island (Aeolian archipelago) identified by activity-based metagenomics and biochemical characterization of new esterases and an arabinopyranosidase. Appl. Microbiol. Biotechnol. 2015, 99, 10031-10046. [CrossRef] [PubMed]

57. Leis, B.; Heinze, S.; Angelov, A.; Pham, V.T.T.; Thürmer, A.; Jebbar, M.; Golyshin, P.N.; Streit, W.R.; Daniel, R.; Liebl, W. Functional Screening of Hydrolytic Activities Reveals an Extremely Thermostable Cellulase from a Deep-Sea Archaeon. Front. Bioeng. Biotechnol. 2015, 3, 95. [CrossRef] [PubMed] 
58. Graham, J.E.; Clark, M.E.; Nadler, D.C.; Huffer, S.; Chokhawala, H.A.; Rowland, S.E.; Blanch, H.W.; Clark, D.S.; Robb, F.T. Identification and characterization of a multidomain hyperthermophilic cellulase from an archaeal enrichment. Nat. Commun. 2011, 2, 375. [CrossRef] [PubMed]

59. Schröder, C.; Elleuche, S.; Blank, S.; Antranikian, G. Characterization of a heat-active archaeal $\beta$-glucosidase from a hydrothermal spring metagenome. Enzyme Microb. Technol. 2014, 57, 48-54. [CrossRef] [PubMed]

60. Yasir, M.; Khan, H.; Azam, S.S.; Telke, A.; Kim, S.W.; Chung, Y.R. Cloning and functional characterization of endo- $\beta-1,4$-glucanase gene from metagenomic library of vermicompost. J. Microbiol. 2013, 51, 329-335. [CrossRef] [PubMed]

61. Kwon, E.J.; Jeong, Y.S.; Kim, Y.H.; Kim, S.K.; Na, H.B.; Kim, J.; Yun, H.D.; Kim, H. Construction of a Metagenomic Library from Compost and Screening of Cellulase- and Xylanase-positive Clones. J. Korean Soc. Appl. Biol. Chem. 2010, 53, 702-708. [CrossRef]

62. Okano, H.; Ozaki, M.; Kanaya, E.; Kim, J.-J.; Angkawidjaja, C.; Koga, Y.; Kanaya, S. Structure and stability of metagenome-derived glycoside hydrolase family 12 cellulase (LC-CelA) a homolog of Cel12A from Rhodothermus marinus. FEBS Open Bio 2014, 4, 936-946. [CrossRef] [PubMed]

63. Yan, X.; Geng, A.; Zhang, J.; Wei, Y.; Zhang, L.; Qian, C.; Wang, Q.; Wang, S.; Zhou, Z. Discovery of (hemi-)cellulase genes in a metagenomic library from a biogas digester using 454 pyrosequencing. Appl. Microbiol. Biotechnol. 2013, 97, 8173-8182. [CrossRef] [PubMed]

64. Alvarez, T.M.; Paiva, J.H.; Ruiz, D.M.; Cairo, J.P.L.F.; Pereira, I.O.; Paixão, D.A.A.; de Almeida, R.F.; Tonoli, C.C.C.; Ruller, R.; Santos, C.R.; et al. Structure and function of a novel cellulase 5 from sugarcane soil metagenome. PLoS ONE 2013, 8, e83635. [CrossRef] [PubMed]

65. Liu, J.; Liu, W.-D.; Zhao, X.-L.; Shen, W.-J.; Cao, H.; Cui, Z.-L. Cloning and functional characterization of a novel endo- $\beta-1,4$-glucanase gene from a soil-derived metagenomic library. Appl. Microbiol. Biotechnol. 2011, 89, 1083-1092. [CrossRef] [PubMed]

66. Pottkämper, J.; Barthen, P.; Ilmberger, N.; Schwaneberg, U.; Schenk, A.; Schulte, M.; Ignatiev, N.; Streit, W.R. Applying metagenomics for the identification of bacterial cellulases that are stable in ionic liquids. Green Chem. 2009, 11, 957. [CrossRef]

67. Feng, Y.; Duan, C.-J.; Pang, H.; Mo, X.-C.; Wu, C.-F.; Yu, Y.; Hu, Y.-L.; Wei, J.; Tang, J.-L.; Feng, J.-X. Cloning and identification of novel cellulase genes from uncultured microorganisms in rabbit cecum and characterization of the expressed cellulases. Appl. Microbiol. Biotechnol. 2007, 75, 319-328. [CrossRef] [PubMed]

68. Del Pozo, M.V.; Fernández-Arrojo, L.; Gil-Martínez, J.; Montesinos, A.; Chernikova, T.N.; Nechitaylo, T.Y.; Waliszek, A.; Tortajada, M.; Rojas, A.; Huws, S.A.; et al. Microbial $\beta$-glucosidases from cow rumen metagenome enhance the saccharification of lignocellulose in combination with commercial cellulase cocktail. Biotechnol. Biofuels 2012, 5, 73. [CrossRef] [PubMed]

69. Ramírez-Escudero, M.; Del Pozo, M.V.; Marín-Navarro, J.; González, B.; Golyshin, P.N.; Polaina, J.; Ferrer, M.; Sanz-Aparicio, J. Structural and Functional Characterization of a Ruminal $\beta$-Glycosidase Defines a Novel Subfamily of Glycoside Hydrolase Family 3 with Permuted Domain Topology. J. Biol. Chem. 2016, 291, 24200-24214. [CrossRef] [PubMed]

70. Beloqui, A.; Nechitaylo, T.Y.; López-Cortés, N.; Ghazi, A.; Guazzaroni, M.-E.; Polaina, J.; Strittmatter, A.W.; Reva, O.; Waliczek, A.; Yakimov, M.M.; et al. Diversity of glycosyl hydrolases from cellulose-depleting communities enriched from casts of two earthworm species. Appl. Environ. Microbiol. 2010, 76, 5934-5946. [CrossRef] [PubMed]

71. Wang, Q.; Qian, C.; Zhang, X.-Z.; Liu, N.; Liu, N.; Yan, X.; Zhou, Z. Characterization of a novel thermostable $\beta$-glucosidase from a metagenomic library of termite gut. Enzyme Microb. Technol. 2012, 51, 319-324. [CrossRef] [PubMed]

72. Zhang, M.; Liu, N.; Qian, C.; Wang, Q.; Wang, Q.; Long, Y.; Huang, Y.; Zhou, Z.; Yan, X. Phylogenetic and functional analysis of gut microbiota of a fungus-growing higher termite: Bacteroidetes from higher termites are a rich source of $\beta$-glucosidase genes. Microb. Ecol. 2014, 68, 416-425. [CrossRef] [PubMed]

73. Himmel, M.E.; Adney, W.S.; Tucker, M.P.; Grohmann, K. Thermostable Purified Endoglucanas from Acidothermus cellulolyticus ATCC 43068. U.S. Patent 5,275,944, 4 January 1994.

74. Nurachman, Z.; Kurniasih, S.D.; Puspitawati, F.; Hadi, S.; Radjasa, O.K.; Natalia, D. Cloning of the Endoglucanase Gene from a Bacillus amyloliquefaciens PSM 3.1 in Escherichia coli Revealed Catalytic Triad Residues Thr-His-Glu. Am. J. Biochem. Biotechnol. 2010, 6, 268-274. [CrossRef] 
75. Bischoff, K.M.; Rooney, A.P.; Li, X.-L.; Liu, S.; Hughes, S.R. Purification and characterization of a family 5 endoglucanase from a moderately thermophilic strain of Bacillus licheniformis. Biotechnol. Lett. 2006, 28, 1761-1765. [CrossRef] [PubMed]

76. Jung, Y.-J.; Lee, Y.-S.; Park, I.-H.; Chandra, M.S.; Kim, K.-K.; Choi, Y.-L. Molecular cloning, purification and characterization of thermostable beta-1,3-1,4 glucanase from Bacillus subtilis A8-8. Indian J. Biochem. Biophys. 2010, 47, 203-210. [PubMed]

77. Chhabra, S.R.; Shockley, K.R.; Ward, D.E.; Kelly, R.M. Regulation of endo-acting glycosyl hydrolases in the hyperthermophilic bacterium Thermotoga maritima grown on glucan- and mannan-based polysaccharides. Appl. Environ. Microbiol. 2002, 68, 545-554. [CrossRef] [PubMed]

78. Bauer, S.; Vasu, P.; Persson, S.; Mort, A.J.; Somerville, C.R. Development and application of a suite of polysaccharide-degrading enzymes for analyzing plant cell walls. Proc. Natl. Acad. Sci. USA 2006, 103, 11417-11422. [CrossRef] [PubMed]

79. Calza, R.E.; Irwin, D.C.; Wilson, D.B. Purification and characterization of two $\beta-1,4$-endoglucanases from Thermomonospora fusca. Biochemistry 1985, 24, 7797-7804. [CrossRef]

80. Yin, Y.-R.; Zhang, F.; Hu, Q.-W.; Xian, W.-D.; Hozzein, W.N.; Zhou, E.-M.; Ming, H.; Nie, G.-X.; Li, W.-J. Heterologous expression and characterization of a novel halotolerant, thermostable, and alkali-stable GH6 endoglucanase from Thermobifida halotolerans. Biotechnol. Lett. 2015, 37, 857-862. [CrossRef] [PubMed]

81. Cazemier, A.E.; Verdoes, J.C.; Op den Camp, H.J.M.; Hackstein, J.H.P.; van Ooyen, A.J. A beta-1,4-endoglucanase-encoding gene from Cellulomonas pachnodae. Appl. Microbiol. Biotechnol. 1999, 52, 232-239. [CrossRef] [PubMed]

82. Xu, X.; Li, J.; Zhang, W.; Huang, H.; Shi, P.; Luo, H.; Liu, B.; Zhang, Y.; Zhang, Z.; Fan, Y.; et al. A Neutral Thermostable $\beta-1,4-G l u c a n a s e$ from Humicola insolens Y1 with Potential for Applications in Various Industries. PLoS ONE 2015, 10, e0124925. [CrossRef] [PubMed]

83. Li, X.L.; Chen, H.; Ljungdahl, L.G. Two cellulases, CelA and CelC, from the polycentric anaerobic fungus Orpinomyces strain PC-2 contain N-terminal docking domains for a cellulase-hemicellulase complex. Appl. Environ. Microbiol. 1997, 63, 4721-4728. [PubMed]

84. Takashima, S.; Nakamura, A.; Hidaka, M.; Masaki, H.; Uozumi, T. Cloning, sequencing, and expression of the cellulase genes of Humicola grisea var. thermoidea. J. Biotechnol. 1996, 50, 137-147. [CrossRef]

85. Wei, X.-M.; Qin, Y.; Qu, Y. Molecular Cloning and Characterization of Two Major Endoglucanases from Penicillium decumbens. J. Microbiol. Biotechnol. 2010, 20, 265-270. [CrossRef] [PubMed]

86. Miettinen-Oinonen, A.; Londesborough, J.; Joutsjoki, V.; Lantto, R.; Vehmaanperä, J. Three cellulases from Melanocarpus albomyces for textile treatment at neutral pH. Enzyme Microb. Technol. 2004, 34, 332-341. [CrossRef]

87. Yoo, J.-S.; Jung, Y.-J.; Chung, S.-Y.; Lee, Y.-C.; Choi, Y.-L. Molecular cloning and characterization of CMCase gene (celC) from Salmonella typhimurium UR. J. Microbiol. 2004, 42, 205-210. [PubMed]

88. Kim, J.O.; Park, S.R.; Lim, W.J.; Ryu, S.K.; Kim, M.K.; An, C.L.; Cho, S.J.; Park, Y.W.; Kim, J.H.; Yun, H.D. Cloning and characterization of thermostable endoglucanase (Cel8Y) from the hyperthermophilic Aquifex aeolicus VF5. Biochem. Biophys. Res. Commun. 2000, 279, 420-426. [CrossRef] [PubMed]

89. Hakamada, Y.; Endo, K.; Takizawa, S.; Kobayashi, T.; Shirai, T.; Yamane, T.; Ito, S. Enzymatic properties, crystallization, and deduced amino acid sequence of an alkaline endoglucanase from Bacillus circulans. Biochim. Biophys. Acta 2002, 1570, 174-180. [CrossRef]

90. Ul Haq, I.; Akram, F.; Khan, M.A.; Hussain, Z.; Nawaz, A.; Iqbal, K.; Shah, A.J. CenC, a multidomain thermostable GH9 processive endoglucanase from Clostridium thermocellum: Cloning, characterization and saccharification studies. World J. Microbiol. Biotechnol. 2015, 31, 1699-1710. [CrossRef] [PubMed]

91. Zverlov, V.; Mahr, S.; Riedel, K.; Bronnenmeier, K. Properties and gene structure of a bifunctional cellulolytic enzyme (CelA) from the extreme thermophile "Anaerocellum thermophilum" with separate glycosyl hydrolase family 9 and 48 catalytic domains. Microbiology 1998, 144, 457-465. [CrossRef] [PubMed]

92. Zhang, X.-Z.; Sathitsuksanoh, N.; Zhang, Y.-H.P. Glycoside hydrolase family 9 processive endoglucanase from Clostridium phytofermentans: Heterologous expression, characterization, and synergy with family 48 cellobiohydrolase. Bioresour. Technol. 2010, 101, 5534-5538. [CrossRef] [PubMed]

93. Liebl, W.; Ruile, P.; Bronnenmeier, K.; Riedel, K.; Lottspeich, F.; Greif, I. Analysis of a Thermotoga maritima DNA fragment encoding two similar thermostable cellulases, CelA and CelB, and characterization of the recombinant enzymes. Microbiology 1996, 142, 2533-2542. [CrossRef] [PubMed] 
94. Bauer, M.W.; Driskill, L.E.; Callen, W.; Snead, M.A.; Mathur, E.J.; Kelly, R.M. An Endoglucanase, EglA, from the Hyperthermophilic Archaeon Pyrococcus Furiosus Hydrolyzes $\beta-1,4$ Bonds in Mixed-Linkage $(1 \rightarrow 3),(1 \rightarrow 4)-\beta-D-G l u c a n s$ and Cellulose. J. Bacteriol. 1999, 181, 284-290. [PubMed]

95. Huang, Y.; Krauss, G.; Cottaz, S.; Driguez, H.; Lipps, G. A highly acid-stable and thermostable endo-beta-glucanase from the thermoacidophilic archaeon Sulfolobus solfataricus. Biochem. J. 2005, 385, 581-588. [CrossRef] [PubMed]

96. Irdani, T.; Perito, B.; Mastromei, G. Characterization of a Streptomyces rochei endoglucanase. Ann. N. Y. Acad. Sci. 1996, 782, 173-181. [CrossRef] [PubMed]

97. Karlsson, J.; Siika-aho, M.; Tenkanen, M.; Tjerneld, F. Enzymatic properties of the low molecular mass endoglucanases Cel12A (EG III) and Cel45A (EG V) of Trichoderma reesei. J. Biotechnol. 2002, 99, 63-78. [CrossRef]

98. Warner, C.D.; Hoy, J.A.; Shilling, T.C.; Linnen, M.J.; Ginder, N.D.; Ford, C.F.; Honzatko, R.B.; Reilly, P.J. Tertiary structure and characterization of a glycoside hydrolase family 44 endoglucanase from Clostridium acetobutylicum. Appl. Environ. Microbiol. 2010, 76, 338-346. [CrossRef] [PubMed]

99. Hansen, C.K.; Diderichsen, B.; Jørgensen, P.L. celA from Bacillus lautus PL236 encodes a novel cellulose-binding endo-beta-1,4-glucanase. J. Bacteriol. 1992, 174, 3522-3531. [CrossRef] [PubMed]

100. Ahsan, M.M.; Matsumoto, M.; Karita, S.; Kimura, T.; Sakka, K.; Ohmiya, K. Purification and Characterization of the Family J Catalytic Domain Derived from the Clostridium thermocellum Endoglucanase CelJ. Biosci. Biotechnol. Biochem. 1997, 61, 427-431. [CrossRef] [PubMed]

101. Koga, J.; Baba, Y.; Shimonaka, A.; Nishimura, T.; Hanamura, S.; Kono, T. Purification and characterization of a new family 45 endoglucanase, STCE1, from Staphylotrichum coccosporum and its overproduction in Humicola insolens. Appl. Environ. Microbiol. 2008, 74, 4210-4217. [CrossRef] [PubMed]

102. Wonganu, B.; Pootanakit, K.; Boonyapakron, K.; Champreda, V.; Tanapongpipat, S.; Eurwilaichitr, L. Cloning, expression and characterization of a thermotolerant endoglucanase from Syncephalastrum racemosum (BCC18080) in Pichia pastoris. Protein Expr. Purif. 2008, 58, 78-86. [CrossRef] [PubMed]

103. Baba, Y.; Shimonaka, A.; Koga, J.; Murashima, K.; Kubota, H.; Kono, T. Purification and characterization of a new endo-1,4-beta-D-glucanase from Beltraniella portoricensis. Biosci. Biotechnol. Biochem. 2005, 69, 1198-1201. [CrossRef] [PubMed]

104. Eckert, K.; Schneider, E. A thermoacidophilic endoglucanase (CelB) from Alicyclobacillus acidocaldarius displays high sequence similarity to arabinofuranosidases belonging to family 51 of glycoside hydrolases. Eur. J. Biochem. 2003, 270, 3593-3602. [CrossRef] [PubMed]

105. Brás, J.L.A.; Cartmell, A.; Carvalho, A.L.M.; Verzé, G.; Bayer, E.A.; Vazana, Y.; Correia, M.A.S.; Prates, J.A.M.; Ratnaparkhe, S.; Boraston, A.B.; et al. Structural insights into a unique cellulase fold and mechanism of cellulose hydrolysis. Proc. Natl. Acad. Sci. USA 2011, 108, 5237-5242. [CrossRef] [PubMed]

106. Park, C.-S.; Kawaguchi, T.; Sumitani, J.-I.; Takada, G.; Izumori, K.; Arai, M. Cloning and sequencing of an exoglucanase gene from Streptomyces sp. M 23, and its expression in Streptomyces lividans TK-24. J. Biosci. Bioeng. 2005, 99, 434-436. [CrossRef] [PubMed]

107. Zhang, S.; Lao, G.; Wilson, D.B. Characterization of a Thermomonospora fusca exocellulase. Biochemistry 1995, 34, 3386-3395. [CrossRef] [PubMed]

108. Liu, S.-A.; Li, D.-C.; Er, S.-J.; Zhang, Y. Cloning and expressing of cellulase gene (cbh2) from thermophilic fungi Chaetomium thermophilum CT2. Sheng Wu Gong Cheng Xue Bao 2005, 21, 892-899. [PubMed]

109. Bukhtojarov, F.E.; Ustinov, B.B.; Salanovich, T.N.; Antonov, A.I.; Gusakov, A.V.; Okunev, O.N.; Sinitsyn, A.P. Cellulase complex of the fungus Chrysosporium lucknowense: Isolation and characterization of endoglucanases and cellobiohydrolases. Biochemistry. 2004, 69, 542-551. [CrossRef] [PubMed]

110. Toda, H.; Nagahata, N.; Amano, Y.; Nozaki, K.; Kanda, T.; Okazaki, M.; Shimosaka, M. Gene cloning of cellobiohydrolase II from the white rot fungus Irpex lacteus MC-2 and its expression in Pichia pastoris. Biosci. Biotechnol. Biochem. 2008, 72, 3142-3147. [CrossRef] [PubMed]

111. Gao, L.; Wang, F.; Gao, F.; Wang, L.; Zhao, J.; Qu, Y. Purification and characterization of a novel cellobiohydrolase (PdCel6A) from Penicillium decumbens JU-A10 for bioethanol production. Bioresour. Technol. 2011, 102, 8339-8342. [CrossRef] [PubMed]

112. Song, J.; Liu, B.; Liu, Z.; Yang, Q. Cloning of two cellobiohydrolase genes from Trichoderma viride and heterogenous expression in yeast Saccharomyces cerevisiae. Mol. Biol. Rep. 2010, 37, 2135-2140. [CrossRef] [PubMed] 
113. Singh, R.N.; Akimenko, V.K. Isolation of a Cellobiohydrolase of Clostridium thermocellum Capable of Degrading Natural Crystalline Substrates. Biochem. Biophys. Res. Commun. 1993, 192, 1123-1130. [CrossRef] [PubMed]

114. Kataeva, I.; Li, X.-L.; Chen, H.; Choi, S.-K.; Ljungdahl, L.G. Cloning and sequence analysis of a new cellulase gene encoding CelK, a major cellulosome component of Clostridium thermocellum: Evidence for gene duplication and recombination. J. Bacteriol. 1999, 181, 5288-5295. [PubMed]

115. Zverlov, V.V.; Velikodvorskaya, G.A.; Schwarz, W.H. A newly described cellulosomal cellobiohydrolase, $\mathrm{CelO}$, from Clostridium thermocellum: Investigation of the exo-mode of hydrolysis, and binding capacity to crystalline cellulose. Microbiology 2002, 148, 247-255. [CrossRef] [PubMed]

116. Takada, G.; Kawaguchi, T.; Sumitani, J.; Arai, M. Expression of Aspergillus aculeatus No. F-50 cellobiohydrolase I (cbhI) and beta-glucosidase 1 (bgl1) genes by Saccharomyces cerevisiae. Biosci. Biotechnol. Biochem. 1998, 62, 1615-1618. [CrossRef] [PubMed]

117. Moroz, O.V.; Maranta, M.; Shaghasi, T.; Harris, P.V.; Wilson, K.S.; Davies, G.J. The three-dimensional structure of the cellobiohydrolase Cel7A from Aspergillus fumigatus at $1.5 \AA$ A resolution. Acta Crystallogr. Sect. F Struct. Biol. Commun. 2015, 71, 114-120. [CrossRef] [PubMed]

118. Li, Y.; Li, D.; Teng, F. Purification and characterization of a cellobiohydrolase from the thermophilic fungus Chaetomium thermophilus CT2. Wei Sheng Wu Xue Bao 2006, 46, 143-146. [PubMed]

119. Hobdey, S.E.; Knott, B.C.; Haddad Momeni, M.; Taylor, L.E.; Borisova, A.S.; Podkaminer, K.K.; VanderWall, T.A.; Himmel, M.E.; Decker, S.R.; Beckham, G.T.; et al. Biochemical and Structural Characterizations of Two Dictyostelium Cellobiohydrolases from the Amoebozoa Kingdom Reveal a High Level of Conservation between Distant Phylogenetic Trees of Life. Appl. Environ. Microbiol. 2016, 82, 3395-3409. [CrossRef] [PubMed]

120. Takashima, S.; Iikura, H.; Nakamura, A.; Hidaka, M.; Masaki, H.; Uozumi, T. Isolation of the gene and characterization of the enzymatic properties of a major exoglucanase of Humicola grisea without a cellulose-binding domain. J. Biochem. 1998, 124, 717-725. [CrossRef] [PubMed]

121. Voutilainen, S.P.; Boer, H.; Linder, M.B.; Puranen, T.; Rouvinen, J.; Vehmaanperä, J.; Koivula, A. Heterologous expression of Melanocarpus albomyces cellobiohydrolase Cel7B, and random mutagenesis to improve its thermostability. Enzyme Microb. Technol. 2007, 41, 234-243. [CrossRef]

122. Texier, H.; Dumon, C.; Neugnot-Roux, V.; Maestracci, M.; O’Donohue, M.J. Redefining XynA from Penicillium funiculosum IMI 378536 as a GH7 cellobiohydrolase. J. Ind. Microbiol. Biotechnol. 2012, 39, 1569-1576. [CrossRef] [PubMed]

123. Colussi, F.; Serpa, V.; Delabona, P.D.S.; Manzine, L.R.; Voltatodio, M.L.; Alves, R.; Mello, B.L.; Pereira, N.; Farinas, C.S.; Golubev, A.M.; et al. Purification, and biochemical and biophysical characterization of cellobiohydrolase I from Trichoderma harzianum IOC 3844. J. Microbiol. Biotechnol. 2011, 21, 808-817. [CrossRef] [PubMed]

124. Bronnenmeier, K.; Rücknagel, K.P.; Staudenbauer, W.L. Purification and properties of a novel type of exo-1,4-beta-glucanase (avicelase II) from the cellulolytic thermophile Clostridium stercorarium. Eur. J. Biochem. 1991, 200, 379-385. [CrossRef] [PubMed]

125. Zhang, X.-Z.; Zhang, Z.; Zhu, Z.; Sathitsuksanoh, N.; Yang, Y.; Zhang, Y.-H.P. The noncellulosomal family 48 cellobiohydrolase from Clostridium phytofermentans ISDg: Heterologous expression, characterization, and processivity. Appl. Microbiol. Biotechnol. 2010, 86, 525-533. [CrossRef] [PubMed]

126. Kruus, K.; Wang, W.K.; Ching, J.; Wu, J.H.D. Exoglucanase activities of the recombinant Clostridium thermocellum CelS, a major cellulosome component. J. Bacteriol. 1995, 177, 1641-1644. [CrossRef] [PubMed]

127. Liu, W.; Bevan, D.R.; Zhang, Y.-H.P. The family 1 glycoside hydrolase from Clostridium cellulolyticum H10 is a cellodextrin glucohydrolase. Appl. Biochem. Biotechnol. 2010, 161, 264-273. [CrossRef] [PubMed]

128. Yernool, D.A.; McCarthy, J.K.; Eveleigh, D.E.; Bok, J.D. Cloning and characterization of the glucooligosaccharide catabolic pathway $\beta$-glucan glucohydrolase and cellobiose phosphorylase in the marine hyperthermophile Thermotoga neapolitana. J. Bacteriol. 2000, 182, 5172-5179. [CrossRef] [PubMed]

129. Kengen, S.W.M.; Luesink, E.J.; Stams, A.J.M.; Zehnder, A.J.B. Purification and characterization of an extremely thermostable $\beta$-glucosidase from the hyperthermophilic archaeon Pyrococcus furiosus. Eur. J. Biochem. 1993, 213, 305-312. [CrossRef] [PubMed] 
130. Kim, Y.J.; Lee, J.E.; Lee, H.S.; Kwon, K.K.; Kang, S.G.; Lee, J. Novel substrate specificity of a thermostable $\beta$-glucosidase from the hyperthermophilic archaeon, Thermococcus pacificus P-4. Korean J. Microbiol. 2015, 51, 68-74. [CrossRef]

131. Matsui, I.; Sakai, Y.; Matsui, E.; Kikuchi, H.; Kawarabayasi, Y.; Honda, K. Novel substrate specificity of a membrane-bound beta-glycosidase from the hyperthermophilic archaeon Pyrococcus horikoshii. FEBS Lett. 2000, 467, 195-200. [CrossRef]

132. Wu, Y.; Yuan, S.; Chen, S.; Wu, D.; Chen, J.; Wu, J. Enhancing the production of galacto-oligosaccharides by mutagenesis of Sulfolobus solfataricus $\beta$-galactosidase. Food Chem. 2013, 138, 1588-1595. [CrossRef] [PubMed]

133. Sinha, S.K.; Datta, S. $\beta$-Glucosidase from the hyperthermophilic archaeon Thermococcus sp. is a salt-tolerant enzyme that is stabilized by its reaction product glucose. Appl. Microbiol. Biotechnol. 2016, 100, 8399-8409. [CrossRef] [PubMed]

134. Di Lauro, B.; Rossi, M.; Moracci, M. Characterization of a beta-glycosidase from the thermoacidophilic bacterium Alicyclobacillus acidocaldarius. Extremophiles 2006, 10, 301-310. [CrossRef] [PubMed]

135. Liu, Y.; Li, R.; Wang, J.; Zhang, X.; Jia, R.; Gao, Y.; Peng, H. Increased enzymatic hydrolysis of sugarcane bagasse by a novel glucose- and xylose-stimulated $\beta$-glucosidase from Anoxybacillus flavithermus subsp. yunnanensis E13T. BMC Biochem. 2017, 18, 4. [CrossRef] [PubMed]

136. Paavilainen, S.; Hellman, J.; Korpela, T. Purification, characterization, gene cloning, and sequencing of a new $\beta$-glucosidase from Bacillus circulans subsp. alkalophilus. Appl. Environ. Microbiol. 1993, 59, 927-932. [PubMed]

137. Xu, H.; Xiong, A.-S.; Zhao, W.; Tian, Y.-S.; Peng, R.-H.; Chen, J.-M.; Yao, Q.-H. Characterization of a glucose-, xylose-, sucrose-, and D-galactose-stimulated $\beta$-glucosidase from the alkalophilic bacterium Bacillus halodurans C-125. Curr. Microbiol. 2011, 62, 833-839. [CrossRef] [PubMed]

138. Love, D.R.; Fisher, R.; Bergquist, P.L. Sequence structure and expression of a cloned $\beta$-glucosidase gene from an extreme thermophile. MGG Mol. Gen. Genet. 1988, 213, 84-92. [CrossRef] [PubMed]

139. Kosugi, A.; Arai, T.; Doi, R.H. Degradation of cellulosome-produced cello-oligosaccharides by an extracellular non-cellulosomal beta-glucan glucohydrolase, BglA, from Clostridium cellulovorans. Biochem. Biophys. Res. Commun. 2006, 349, 20-23. [CrossRef] [PubMed]

140. Zou, Z.-Z.; Yu, H.-L.; Li, C.-X.; Zhou, X.-W.; Hayashi, C.; Sun, J.; Liu, B.-H.; Imanaka, T.; Xu, J.-H. A new thermostable $\beta$-glucosidase mined from Dictyoglomus thermophilum: Properties and performance in octyl glucoside synthesis at high temperatures. Bioresour. Technol. 2012, 118, 425-430. [CrossRef] [PubMed]

141. Jabbour, D.; Klippel, B.; Antranikian, G. A novel thermostable and glucose-tolerant $\beta$-glucosidase from Fervidobacterium islandicum. Appl. Microbiol. Biotechnol. 2012, 93, 1947-1956. [CrossRef] [PubMed]

142. Gefen, G.; Anbar, M.; Morag, E.; Lamed, R.; Bayer, E.A. Enhanced cellulose degradation by targeted integration of a cohesin-fused $\beta$-glucosidase into the Clostridium thermocellum cellulosome. Proc. Natl. Acad. Sci. USA 2012, 109, 10298-10303. [CrossRef] [PubMed]

143. Brognaro, H.; Almeida, V.M.; de Araujo, E.A.; Piyadov, V.; Santos, M.A.M.; Marana, S.R.; Polikarpov, I. Biochemical Characterization and Low-Resolution SAXS Molecular Envelope of GH1 $\beta$-Glycosidase from Saccharophagus degradans. Mol. Biotechnol. 2016, 58, 777-788. [CrossRef] [PubMed]

144. Marques, A.R.; Coutinho, P.M.; Videira, P.; Fialho, A.M.; Sá-Correia, I. Sphingomonas paucimobilis $\beta$-glucosidase Bgl1: A member of a new bacterial subfamily in glycoside hydrolase family 1 . Biochem. J. 2003, 370, 793-804. [CrossRef] [PubMed]

145. Perez-Pons, J.A.; Cayetano, A.; Rebordosa, X.; Lloberas, J.; Guasch, A.; Querol, E. A beta-glucosidase gene (bgl3) from Streptomyces sp. strain QM-B814. Molecular cloning, nucleotide sequence, purification and characterization of the encoded enzyme, a new member of family 1 glycosyl hydrolases. Eur. J. Biochem. 1994, 223, 557-565. [CrossRef] [PubMed]

146. Breves, R.; Bronnenmeier, K.; Wild, N.; Lottspeich, F.; Staudenbauer, W.L.; Hofemeister, J. Genes encoding two different $\beta$-glucosidases of Thermoanaerobacter brockii are clustered in a common operon. Appl. Environ. Microbiol. 1997, 63, 3902-3910. [PubMed]

147. Song, X.; Xue, Y.; Wang, Q.; Wu, X. Comparison of three thermostable $\beta$-glucosidases for application in the hydrolysis of soybean isoflavone glycosides. J. Agric. Food Chem. 2011, 59, 1954-1961. [CrossRef] [PubMed]

148. Pei, J.; Pang, Q.; Zhao, L.; Fan, S.; Shi, H. Thermoanaerobacterium thermosaccharolyticum $\beta$-glucosidase: A glucose-tolerant enzyme with high specific activity for cellobiose. Biotechnol. Biofuels 2012, 5, 31. [CrossRef] [PubMed] 
149. Spiridonov, N.A.; Wilson, D.B. Cloning and biochemical characterization of BglC, a beta-glucosidase from the cellulolytic actinomycete Thermobifida fusca. Curr. Microbiol. 2001, 42, 295-301. [CrossRef] [PubMed]

150. Wright, R.M.; Yablonsky, M.D.; Shalita, Z.P.; Goyal, A.K.; Eveleigh, D.E. Cloning, characterization, and nucleotide sequence of a gene encoding Microbispora bispora BglB, a thermostable beta-glucosidase expressed in Escherichia coli. Appl. Environ. Microbiol. 1992, 58, 3455-3465. [PubMed]

151. Haq, I.U.; Khan, M.A.; Muneer, B.; Hussain, Z.; Afzal, S.; Majeed, S.; Rashid, N.; Javed, M.M.; Ahmad, I. Cloning, characterization and molecular docking of a highly thermostable $\beta$-1,4-glucosidase from Thermotoga petrophila. Biotechnol. Lett. 2012, 34, 1703-1709. [CrossRef] [PubMed]

152. Oh, E.-J.; Lee, Y.-J.; Chol, J.J.; Seo, M.S.; Lee, M.S.; Kim, G.A.; Kwon, S.-T. Mutational analysis of Thermus caldophilus GK24 beta-glycosidase: Role of His119 in substrate binding and enzyme activity. J. Microbiol. Biotechnol. 2008, 18, 287-294. [PubMed]

153. Xiangyuan, H.; Shuzheng, Z.; Shoujun, Y. Cloning and expression of thermostable beta-glycosidase gene from Thermus nonproteolyticus HG102 and characterization of recombinant enzyme. Appl. Biochem. Biotechnol. 2001, 94, 243-255. [CrossRef]

154. Kang, S.K.; Cho, K.K.; Ahn, J.K.; Bok, J.D.; Kang, S.H.; Woo, J.H.; Lee, H.G.; You, S.K.; Choi, Y.J. Three forms of thermostable lactose-hydrolase from Thermus sp. IB-21: Cloning, expression, and enzyme characterization. J. Biotechnol. 2005, 116, 337-346. [CrossRef] [PubMed]

155. Nam, E.S.; Kim, M.S.; Lee, H.B.; Ahn, J.K. $\beta$-Glycosidase of Thermus thermophilus KNOUC202: Gene and biochemical properties of the enzyme expressed in Escherichia coli. Appl. Biochem. Microbiol. 2010, 46, 515-524. [CrossRef]

156. Zhao, Z.; Ramachandran, P.; Kim, T.-S.; Chen, Z.; Jeya, M.; Lee, J.-K. Characterization of an acid-tolerant $\beta$-1,4-glucosidase from Fusarium oxysporum and its potential as an animal feed additive. Appl. Microbiol. Biotechnol. 2013, 97, 10003-10011. [CrossRef] [PubMed]

157. Takashima, S.; Nakamura, A.; Hidaka, M.; Masaki, H.; Uozumi, T. Molecular Cloning and Expression of the Novel Fungal -Glucosidase Genes from Humicola grisea and Trichoderma reesei. J. Biochem. 1999, 125, 728-736. [CrossRef] [PubMed]

158. Li, X.-L.; Ljungdahl, L.G.; Ximenes, E.A.; Chen, H.; Felix, C.R.; Cotta, M.A.; Dien, B.S. Properties of a recombinant beta-glucosidase from polycentric anaerobic fungus Orpinomyces PC-2 and its application for cellulose hydrolysis. Appl. Biochem. Biotechnol. 2004, 113, 233-250. [CrossRef]

159. Li, X.; Zhao, J.; Shi, P.; Yang, P.; Wang, Y.; Luo, H.; Yao, B. Molecular cloning and expression of a novel $\beta$-glucosidase gene from Phialophora sp. G5. Appl. Biochem. Biotechnol. 2013, 169, 941-949. [CrossRef] [PubMed]

160. Schröder, C.; Blank, S.; Antranikian, G. First Glycoside Hydrolase Family 2 Enzymes from Thermus antranikianii and Thermus brockianus with $\beta$-Glucosidase Activity. Front. Bioeng. Biotechnol. 2015, 3, 76. [CrossRef] [PubMed]

161. Li, D.; Li, X.; Dang, W.; Tran, P.L.; Park, S.-H.; Oh, B.-C.; Hong, W.-S.; Lee, J.-S.; Park, K.-H. Characterization and application of an acidophilic and thermostable $\beta$-glucosidase from Thermofilum pendens. J. Biosci. Bioeng. 2013, 115, 490-496. [CrossRef] [PubMed]

162. Yan, S.; Wei, P.; Chen, Q.; Chen, X.; Wang, S.; Li, J.; Gao, C. Functional and structural characterization of a $\beta$-glucosidase involved in saponin metabolism from intestinal bacteria. Biochem. Biophys. Res. Commun. 2018, 496, 1349-1356. [CrossRef] [PubMed]

163. Lau, A.T.Y.; Wong, W.K.R. Purification and characterization of a major secretory cellobiase, Cba2, from Cellulomonas biazotea. Protein Expr. Purif. 2001, 23, 159-166. [CrossRef] [PubMed]

164. Gao, J.; Wakarchuk, W. Characterization of five $\beta$-glycoside hydrolases from Cellulomonas fimi ATCC 484. J. Bacteriol. 2014, 196, 4103-4110. [CrossRef] [PubMed]

165. Bronnenmeier, K.; Staudenbauer, W.L. Purification and properties of an extracellular $\beta$-glucosidase from the cellulolytic thermophile Clostridium stercorarium. Appl. Microbiol. Biotechnol. 1988, 28, 380-386. [CrossRef]

166. Li, Y.-K.; Lee, J.-A. Cloning and expression of $\beta$-glucosidase from Flavobacterium meningosepticum: A new member of family B $\beta$-glucosidase. Enzyme Microb. Technol. 1999, 24, 144-150. [CrossRef]

167. Xie, J.; Zhao, D.; Zhao, L.; Pei, J.; Xiao, W.; Ding, G.; Wang, Z. Overexpression and characterization of a Ca ${ }^{2+}$ activated thermostable $\beta$-glucosidase with high ginsenoside $\mathrm{Rb} 1$ to ginsenoside $20(\mathrm{~S})$ - $\mathrm{Rg} 3$ bioconversion productivity. J. Ind. Microbiol. Biotechnol. 2015, 42, 839-850. [CrossRef] [PubMed] 
168. Colabardini, A.C.; Valkonen, M.; Huuskonen, A.; Siika-aho, M.; Koivula, A.; Goldman, G.H.; Saloheimo, M. Expression of Two Novel $\beta$-Glucosidases from Chaetomium atrobrunneum in Trichoderma reesei and Characterization of the Heterologous Protein Products. Mol. Biotechnol. 2016, 58, 821-831. [CrossRef] [PubMed]

169. Liu, D.; Zhang, R.; Yang, X.; Zhang, Z.; Song, S.; Miao, Y.; Shen, Q. Characterization of a thermostable $\beta$-glucosidase from Aspergillus fumigatus Z5, and its functional expression in Pichia pastoris X33. Microb. Cell Fact. 2012, 11, 25. [CrossRef] [PubMed]

170. Xu, R.; Teng, F.; Zhang, C.; Li, D. Cloning of a Gene Encoding $\beta$-Glucosidase from Chaetomium thermophilum CT2 and Its Expression in Pichia pastoris. J. Mol. Microbiol. Biotechnol. 2011, 20, 16-23. [CrossRef] [PubMed]

171. Dotsenko, G.S.; Sinitsyna, O.A.; Hinz, S.W.A.; Wery, J.; Sinitsyn, A.P. Characterization of a GH family 3 $\beta$-glycoside hydrolase from Chrysosporium lucknowense and its application to the hydrolysis of $\beta$-glucan and xylan. Bioresour. Technol. 2012, 112, 345-349. [CrossRef] [PubMed]

172. Pei, X.; Zhao, J.; Cai, P.; Sun, W.; Ren, J.; Wu, Q.; Zhang, S.; Tian, C. Heterologous expression of a GH3 $\beta$-glucosidase from Neurospora crassa in Pichia pastoris with high purity and its application in the hydrolysis of soybean isoflavone glycosides. Protein Expr. Purif. 2016, 119, 75-84. [CrossRef] [PubMed]

173. Kato, Y.; Nomura, T.; Ogita, S.; Takano, M.; Hoshino, K. Two new $\beta$-glucosidases from ethanol-fermenting fungus Mucor circinelloides NBRC 4572: Enzyme purification, functional characterization, and molecular cloning of the gene. Appl. Microbiol. Biotechnol. 2013, 97, 10045-10056. [CrossRef] [PubMed]

174. Yang, X.; Ma, R.; Shi, P.; Huang, H.; Bai, Y.; Wang, Y.; Yang, P.; Fan, Y.; Yao, B. Molecular characterization of a highly-active thermophilic $\beta$-glucosidase from Neosartorya fischeri P1 and its application in the hydrolysis of soybean isoflavone glycosides. PLoS ONE 2014, 9, e106785. [CrossRef] [PubMed]

175. Krogh, K.B.R.M.; Harris, P.V.; Olsen, C.L.; Johansen, K.S.; Hojer-Pedersen, J.; Borjesson, J.; Olsson, L. Characterization and kinetic analysis of a thermostable GH3 $\beta$-glucosidase from Penicillium brasilianum. Appl. Microbiol. Biotechnol. 2010, 86, 143-154. [CrossRef] [PubMed]

176. Chen, M.; Qin, Y.; Liu, Z.; Liu, K.; Wang, F.; Qu, Y. Isolation and characterization of a $\beta$-glucosidase from Penicillium decumbens and improving hydrolysis of corncob residue by using it as cellulase supplementation. Enzyme Microb. Technol. 2010, 46, 444-449. [CrossRef] [PubMed]

177. Machida, M.; Ohtsuki, I.; Fukui, S.; Yamashita, I. Nucleotide sequences of Saccharomycopsis fibuligera genes for extracellular $\beta$-glucosidases as expressed in Saccharomyces cerevisiae. Appl. Environ. Microbiol. 1988, 54, 3147-3155. [PubMed]

178. Murray, P.; Aro, N.; Collins, C.; Grassick, A.; Penttilä, M.; Saloheimo, M.; Tuohy, M. Expression in Trichoderma reesei and characterisation of a thermostable family 3 beta-glucosidase from the moderately thermophilic fungus Talaromyces emersonii. Protein Expr. Purif. 2004, 38, 248-257. [CrossRef] [PubMed]

179. Xia, W.; Xu, X.; Qian, L.; Shi, P.; Bai, Y.; Luo, H.; Ma, R.; Yao, B. Engineering a highly active thermophilic $\beta$-glucosidase to enhance its $\mathrm{pH}$ stability and saccharification performance. Biotechnol. Biofuels 2016, 9, 147. [CrossRef] [PubMed]

180. Hong, J.; Tamaki, H.; Kumagai, H. Cloning and functional expression of thermostable beta-glucosidase gene from Thermoascus aurantiacus. Appl. Microbiol. Biotechnol. 2007, 73, 1331-1339. [CrossRef] [PubMed]

181. Karnaouri, A.; Topakas, E.; Paschos, T.; Taouki, I.; Christakopoulos, P. Cloning, expression and characterization of an ethanol tolerant GH3 $\beta$-glucosidase from Myceliophthora thermophila. PeerJ 2013, 1, e46. [CrossRef] [PubMed]

182. Brunner, F.; Wirtz, W.; Rose, J.K.C.; Darvill, A.G.; Govers, F.; Scheel, D.; Nürnberger, T. A $\beta$-glucosidase/xylosidase from the phytopathogenic oomycete, Phytophthora infestans. Phytochemistry 2002, 59, 689-696. [CrossRef] 
183. Ferrara, M.C.; Cobucci-Ponzano, B.; Carpentieri, A.; Henrissat, B.; Rossi, M.; Amoresano, A.; Moracci, M. The identification and molecular characterization of the first archaeal bifunctional exo- $\beta$-glucosidase/ $\mathrm{N}$-acetyl- $\beta$-glucosaminidase demonstrate that family GH116 is made of three functionally distinct subfamilies. Biochim. Biophys. Acta 2014, 1840, 367-377. [CrossRef] [PubMed]

184. Sansenya, S.; Mutoh, R.; Charoenwattanasatien, R.; Kurisu, G.; Ketudat Cairns, J.R. Expression and crystallization of a bacterial glycoside hydrolase family $116 \beta$-glucosidase from Thermoanaerobacterium xylanolyticum. Acta Crystallogr. Sect. F Struct. Biol. Commun. 2015, 71, 41-44. [CrossRef] [PubMed]

(c) 2018 by the authors. Licensee MDPI, Basel, Switzerland. This article is an open access article distributed under the terms and conditions of the Creative Commons Attribution (CC BY) license (http:/ / creativecommons.org/licenses/by/4.0/). 